\title{
A History of Astronaut Construction of Large Space Structures at NASA Langley Research Center ${ }^{3}$
}

\author{
Judith J. Watson \\ NASA Langley Research Center \\ M/S 190 \\ Hampton, Va. 23681 \\ 757-864-3116 \\ j.j.watson@larc.nasa.gov
}

\author{
Timothy J. Collins \\ NASA Langley Research Center \\ $\mathrm{M} / \mathrm{S} 190$ \\ Hampton, Va. 23681 \\ 757-864-3113 \\ t.j.collins@larc.nasa.gov
}

\author{
Harold G. Bush \\ NASA Langley Research Center \\ M/S 190 \\ Hampton, Va. 23681 \\ 757-864-3099 \\ h.g.bush@larc.nasa.gov
}

\begin{abstract}
During the 1970's through the early 1990's, NASA Langley Research Center (LaRC) conducted studies for the design and construction of large space structures in Low Earth Orbit (LEO). The Langley studies focused on the design and construction of erectable space structures. The construction studies evaluated assembly methods using astronauts with and without mechanized foot-restraints. Astronaut construction was shown to be very effective and efficient when the structure and the construction methods were developed in parallel. This paper presents an overview of the LaRC astronaut construction studies of erectable structures, including a database of assembly rates and lessons learned. In addition this paper presents potential applications of erectable structure assembly methods using EVA astronauts and a suggested integrated approach for construction of large space structures.
\end{abstract}

\section{TABLE OF CONTENTS}

1. INTRODUCTION

2. LARGE SPACE STRUCTURES

3. CONSTRUCTION STUDIES

4. FUTURE APPLICATIONS

5. CONCLUDING REMARKS

\section{INTRODUCTION}

Since the 1960's NASA has considered space missions which require structures that are considerably larger than available launch vehicles. These space structures include large support trusses for orbiting space stations, reflectors for deep-space science studies, reflectors for earth environmental studies, large spacecraft for manned missions to Mars and the Moon, and large, highly loaded aerobrakes. Two examples of these early studies are shown in figure 1, a concept for a large space reflector, and figure 2, a concept for a large communications satellite. Today NASA has many initiatives under study by space science [1], earth science, and manned exploration programs which also require large structures. Some of these potential missions include the Terrestrial Planet Imager (figure 3), filled aperture infrared space telescopes, space solar power platforms (figure 4), and human missions to Mars. These missions require telescopes with apertures greater than 10 meters $(m)$ in diameter, solar array platforms kilometers in dimensions, and aeroshells over $10 \mathrm{~m}$ in diameter. With advances in lightweight structures, and with experience gained from assembly of the International Space Station. (ISS) and servicing missions to Hubble Space Telescope (HST), NASA is again evaluating in-space construction techniques for large space structures.

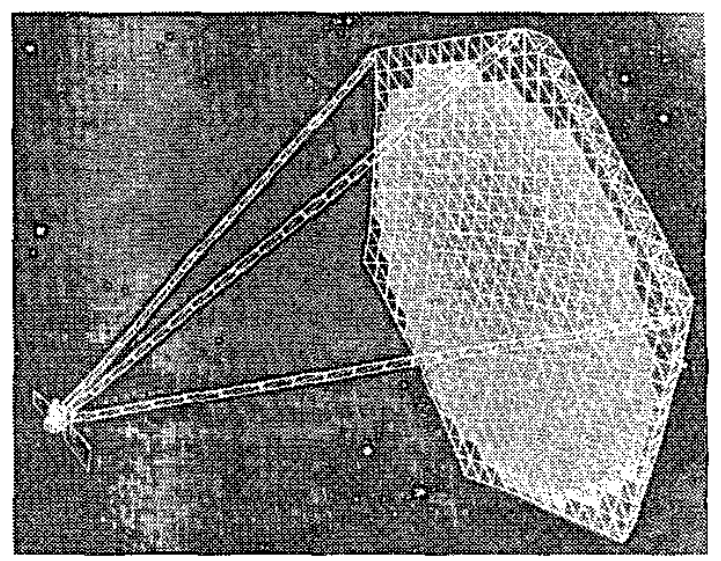

Figure 1 - Early NASA Concept for a Large Space Reflector

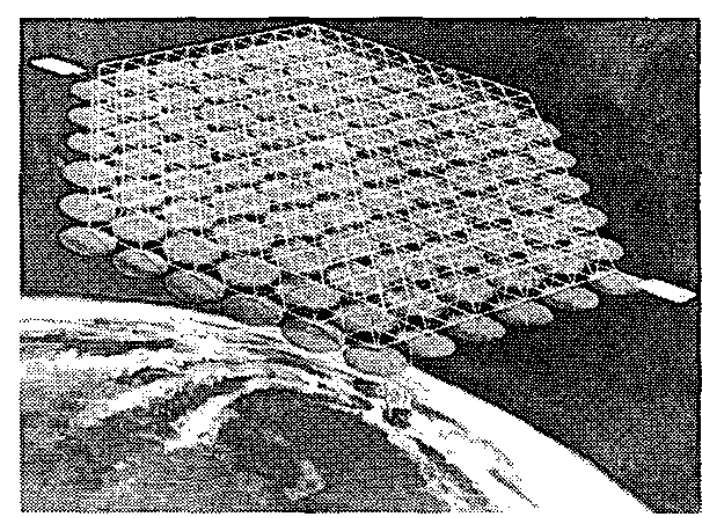

Figure 2 - Early NASA Concept for a Communications Satellite

${ }^{3}$ U.S. Government work not protected by U.S. copyright. 


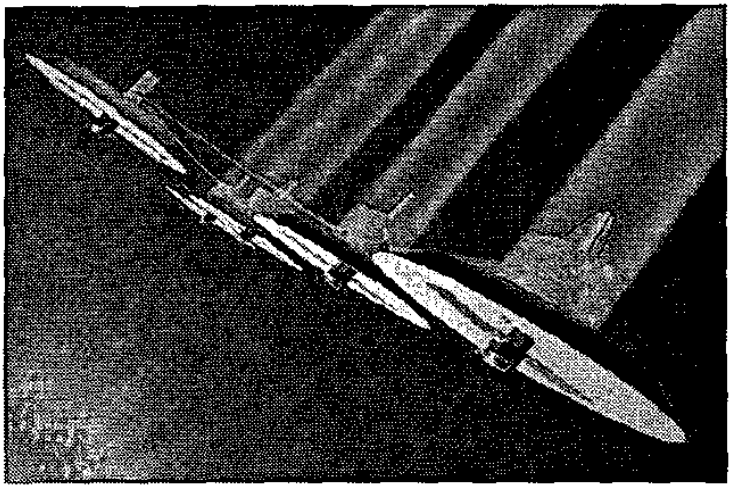

Figure 3 - Concept for Planet Imager Telescope

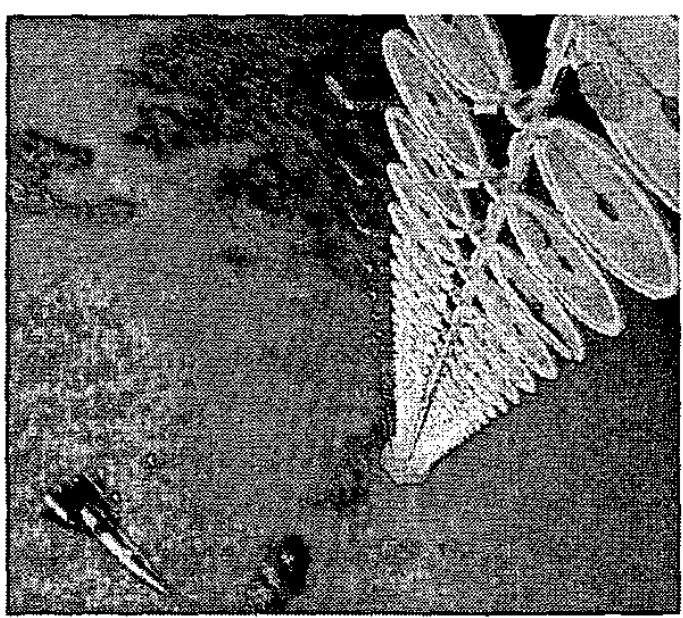

Figure 4 - Concept for Space Solar Power Platform

During the 1970's through the early 1990's, NASA Langley Research Center (LaRC) conducted studies for the design and construction of large space structures in Low Earth Orbit (LEO). The structures considered in the LaRC program were truss structures for beams and planar platforms, and curved support trusses for reflectors. Fullscale structures ranging from $10-15 \mathrm{~m}$ truss beams to a curved reflector truss $14 \mathrm{~m}$ in diameter were evaluated. The studies included $1 \mathrm{-g}$, simulated $0-\mathrm{g}$, and space flight $(0-\mathrm{g})$ tests to verify the assembly methods and the structural hardware.

This paper will present an overview of erectable space structures and astronaut assembly studies developed by LaRC. First, the paper will discuss large space structures by summarizing three construction methods for large space structures and LaRC's selection of erectable structures for astronaut assembly studies. In addition, the structural components developed by LaRC for the erectable assembly will be discussed. Second, the paper will review the LaRC astronaut assembly studies conducted, including a description of each study and the corresponding assembly results and lessons learned. Finally, the paper will present potential applications of the erectable structural assembly using EVA astronauts and a suggested integrated approach for construction of large space structures.

\section{LARGE SPACE STRUCTURES}

\section{Construction Methods}

Studies of the design and construction of large space structures included truss design, launch payload packaging concepts, structural analysis, assembly concepts and proofof concept through ground and flight tests. Early in the studies three different large space structure construction approaches emerged [2]. These methods have been traditionally referred to as: 1) deployable, 2) in-spacefabrication, and 3) erectable. These different methods have been evaluated and each has its advantages and disadvantages. Key discriminators between these approaches are: 1) launch volume packaging, 2) reliability, 3) cost, and 4) impact on the performance of the completed structure.

Deployable-Deployable structures are assembled on Earth, packaged by folding for transportation to orbit in the launch vehicle, and then automatically unfolded or deployed onorbit. As explained in references 3 and 4, deployable structures cover a wide range of spacecraft configurations. To date most of the deployable structures for flight include linearly deployed booms, masts, and hinged panels, umbrella and wrapped-rib antenna mesh surfaces, and simple inflatable shapes. More complex structures such as large planar trusses and large mult-ringed filled aperture reflectors have not been demonstrated but are being investigated. Examples of deployable spacecraft structures are shown in figure 5. Figure 5a shows a concept for a synchronously deployable truss beam. Figure $5 b$ and $5 c$ show deployable booms which are currently space qualified deployable structures. The International Space Station (ISS) solar array boom is a Folding Articulated Square Truss (FAST) mast and the Shuttle Radar Topography Mission (SRTM) boom is an ABLE Deployable Articulated Mast (ADAM) boom, both manufactured by AEC-ABLE. Figure 5d shows an inflatable structure, the Inflatable Antenna Experiment (IAE, manufactured by L'Garde) flown on Space Shuttle flight, STS-77.

The advantages of deployable structures are one, they can package spacecraft or spacecraft components that are dimensionally larger than the launch vehicle shroud into the launch vehicle's payload volume. Second, while launch loads for the packaged spacecraft must be considered in the design, the fully deployed spacecraft can be designed primarily for its operational loads, saving mass and cost. Third, because deployable structures can be automatically deployed in space, no Extravehicular Activity (EVA) and the associated costs and risks of human space flight are required, unless EVA is being considered as a risk mitigation for emergency deployment or repair of the structure. The disadvantages of deployables are their risk 


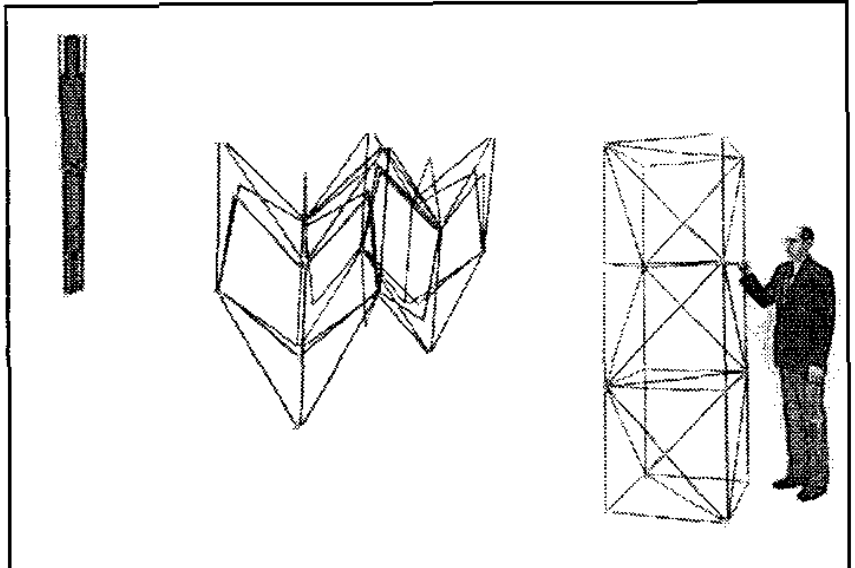

a- Synchronously Deployable PAC Truss

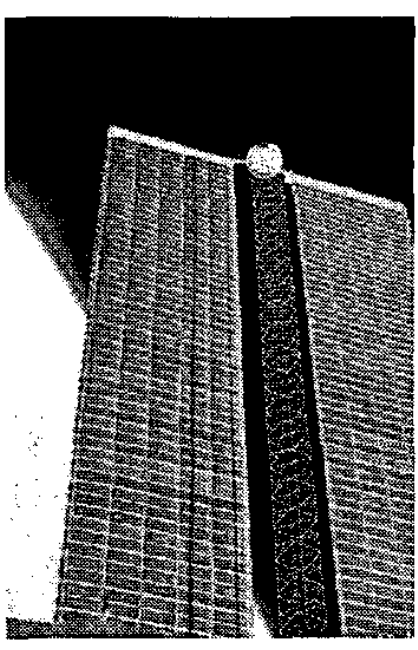

b- ISS Deployable Solar Array Boom

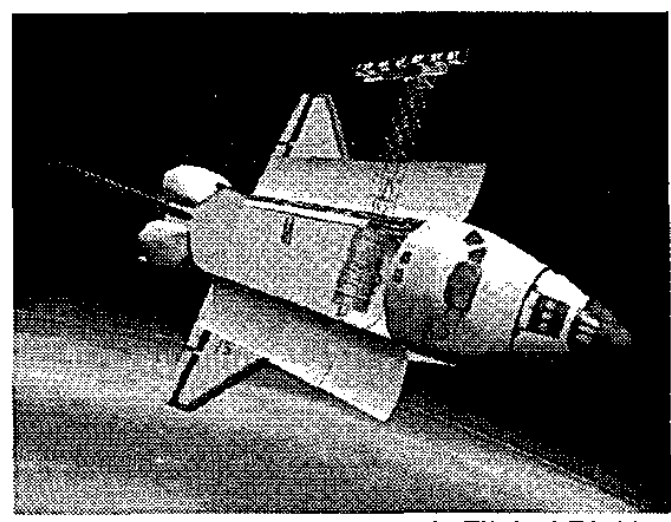

c- SRTM ADAM Boom on Shuttie Flight STS-99

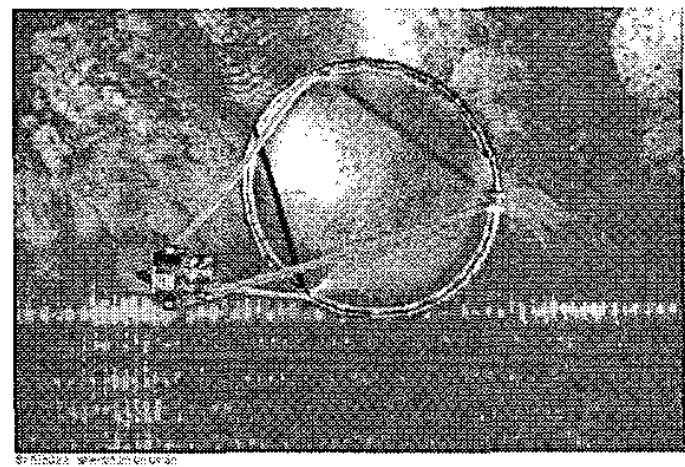

d-. Inflatable Antenna Experiment

Figure 5 - Examples of Deployable Structures

and complexity. If the deploying component does not completely deploy the whole spacecraft can be lost. The complexity of deployable structures can decrease the structural efficiency of the completed structure, although recent advances in precision deployment mechanisms have begun to address this issue [5,6]. In addition, deployable trusses are generally not as efficient for packaging as erectable structures $[7,8]$.

In-space fabrication-In-space fabrication is the fabrication of major structural elements from "raw" materials (shaping and joining flat stock). The fabrication is an automated process that forms "raw" materials into sections of truss beams. After the sections of truss beams are formed the beams are assembled into larger built-up structures such as space platforms. The assembly of the beams into the final structure requires additional automation or EVA astronauts. Two fabrication mechanisms developed and evaluated in the 1970's are described in references 9 and 10 . Figure 6a shows a sketch of a beam builder concept developed by General Dynamics, Convair Division. This concept uses composite material as the raw materiais. Figure $6 \mathrm{~b}$ is a photo of another beam builder developed by Grumman Aerospace Corporation. This concept uses aluminum for the raw material.

The advantages of in-space fabrication are one, high packing density of the raw materials. Second, the beam builder fabricates continuous long beam sections where the longerons (primary axial members) are one continuous piece as opposed to being in sections that must be mechanically joined. Finally, provided the beam builder facility can be launched as a single entity, the only additional components are the pre-packaged raw materials for fabrication. The disadvantages of in-space fabrication include, one, the reliability of the automation of the manufacturing process. Second, thermal gradients during fabrication, particularly in low Earth orbit, can cause the truss beams to be formed with a waviness instead of straight. And 


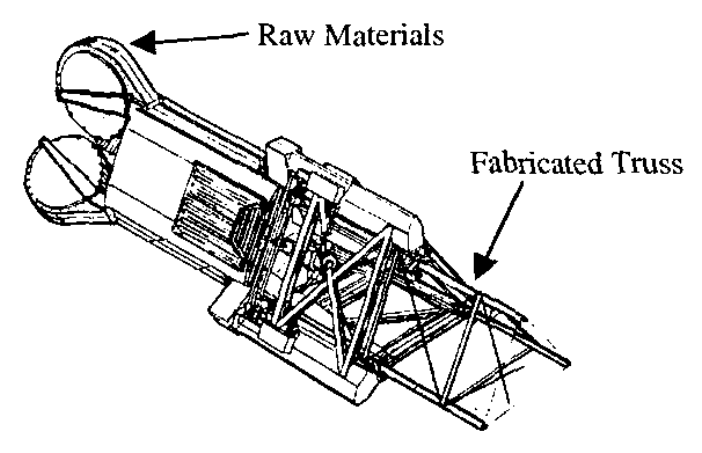

a - In-Space Fabrication Concept

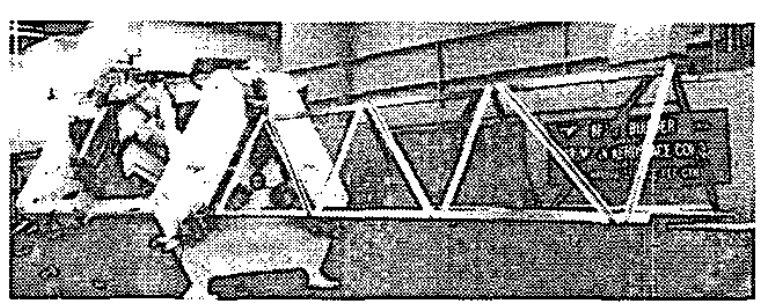

b - Beam Builder Deploying Fabricated Truss Beam

Figure 6 - In-Space Fabrication Machines

third, once the beams are manufactured the construction process requires the additional complexity of assembling the final structure. If EVA is the method of assembly then the costs and risks of human space flight will be a concern.

Erectable-Erectable structures are assembled piece-bypiece on-orbit. The separate components are packaged on Earth into the launch payload. Once in space, the components are taken from the payload bay of a launch vehicle and connected together into the spacecraft structure. The components can be assembled by EVA astronauts, by automated and/or tele-operated robotics, or by a combination of both astronauts and robotics. A photo of an erectable truss structure is shown in figure 7 .

The advantages of erectable structures are their compact packaging capabilities $[7,8]$, high versatility for growth, accommodation of maintenance and repair [3], and relative structural simplicity and good structural performance. The disadvantages associated with erectables are the cost and risk (both real and perceived) of the human EVAs and/or the low technology readiness level of robotic assembly operations. There is some limited flight experience for erectable in-space construction of structures. The assembly of the ISS, and the maintenance and servicing missions to the HST have provided the most experience in EVA operations of large space structures to date.

The NASA Large Space Structures program (1970's1980 's) investigated the three construction methods discussed previously. Because erectable truss structures were structurally simple, demonstrated good structural performance, had the ability to more efficiently package than deployables and utilized the inherent flexibility of the human as an assembly tool, the LaRC large space structures program pursued the assembly of truss structures using the erectable construction method.

\section{Structural Components of Erectable Truss Structures}

As listed in reference 3, large space structures can be categorized as long slender beams, large support platforms, precision reflectors (moderate and high precision), highly loaded aeroshells, in-space construction facilities, and pressurized volumes. The assembly studies at Langley focused on the large support trusses for platforms, beams, and reflectors.

Typical truss structures are comprised of repeating elements or bays, composed of two basic components; the connecting nodes and the strut members as shown in figure 7 . Depending upon the construction method the designs of these components vary. For an erectable truss structure there are typically two components, a strut and a node. The strut is a tube or rod with connecting end joints. The node is the common attachment point for the struts with the attaching end joints. Before assembly methods could be evaluated, the structure and the connecting joints had to be developed. Besides standard uniform cross section struts such as metal or composite tubes another concept developed to facilitate efficient packaging is the nestable column (figure 8). References 11 and 12 describe the details of the nestable colums. The columns are tapered column-halves that can be stowed like stacked "dixie cups". The column-halves are later joined in the center by the center snap- joint.

The development of the connecting joints is a critical part of the assessment of the erectable assembly method. Astronauts wear a bulky pressure suit in the space environment that is pressurized to approximately $4 \mathrm{psi}$. This causes the suit, and in particular the gloves, to become stiff. This stiffness limits the dexterity of the astronaut's hand operations. Therefore, the joint design needs to minimize hand fatigue. The progression of joints developed at LaRC to accommodate astronaut assembly is shown in figure 9 . 


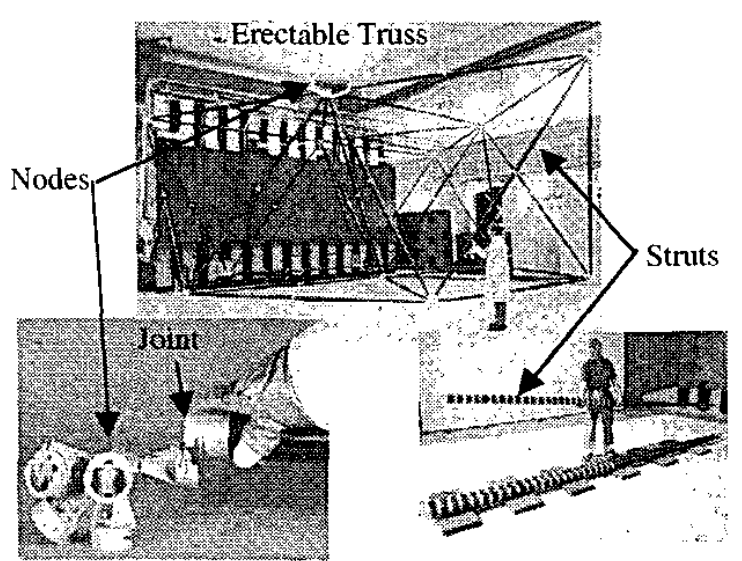

Figure 7 - Erectable Truss Components

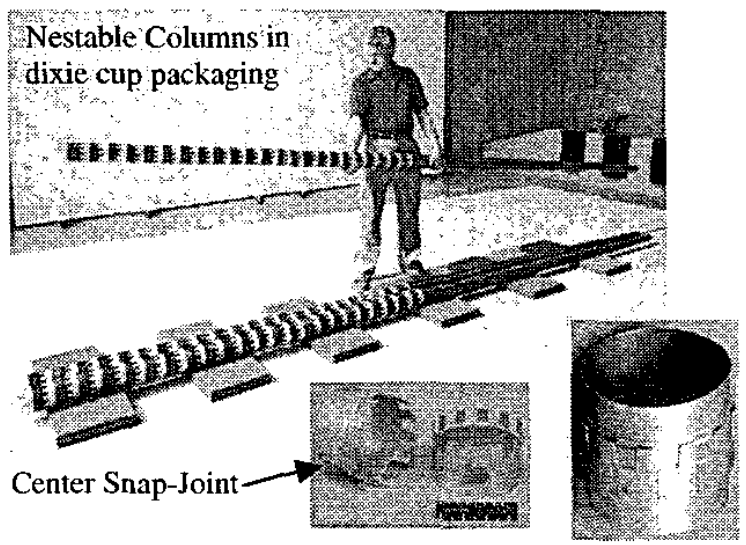

Figure 8 - Nestable Columns

The first joint design was originally designed for use with an automated assembler. However, since the assembler concept was not viable for testing at that time, the joint was used in simulated EVA for quick attachment of truss components in assembly tests. The joint, a snap joint [2], is shown in figure $9 \mathrm{a}$. The joint used a snap together approach for connecting the strut members of the truss. The joint had a tongue and groove design as the loadcarrying path and was approximately 5 centimeters $(\mathrm{cm})$ (2 inches) in diameter. Disassembly required a special tool.

Figure $9 \mathrm{~b}$ shows the next development of the joint, a quick-attachment latch-joint [13]. This joint is designed for quick assembly and disassembly in EVA. The joint has an internal spring-loaded latching pawl. Pressing the latching pawl release lever disassembles the joint.

The joint shown in figure 9c uses the basic side-latching configuration but also includes a spring-loaded collar that snaps up around the joint during assembly $[14,15]$. This is a smaller joint with a diameter of approximately $2.54 \mathrm{~cm}$ (1 inch). The spring-loaded locking sleeve is designed to enable quick release as well as quick attachment of the joint by manual methods. The joint is released by retracting the sleeve and separating the joint halves.

These early joint configurations allowed quick assembly of the truss structures. Although the joints were not designed as structurally linear and predictable in their performance, the assembled structures demonstrated reasonable structural behavior. The next refinement of the joint was to design it not only as an easily assembled quick-attachment joint, but also as a structurally efficient connection with predictable linear structural behavior in the load regime. This was achieved with the joint shown in figure $9 \mathrm{~d}$. The joint maintained the same side latching design. A spring-loaded latch facilitated the quick attachment capability and a hand operated locking collar locked the joint into a structural preload. The preload provided the linear structural performance of the joint.

A pattern was painted on the strut end fitting and on the node end fitting to provide a highly visible lock position indicator. The photographs in figure $9 \mathrm{~d}$ show the sequence of inserting and locking the joint. The joint features a double lock condition which was incorporated to prevent accidental unlocking of the structure after assembly. The joint was first developed as $5 \mathrm{~cm}$ diameter joint [16]. Later a $2.54 \mathrm{~cm}$ version [17], shown in figure 9e, was also developed. The final joint design had evolved to one incorporating easy onehand operations for EVA astronauts with quick-attachment quick-release side-latching operations, and a linearly predictable structural performance.

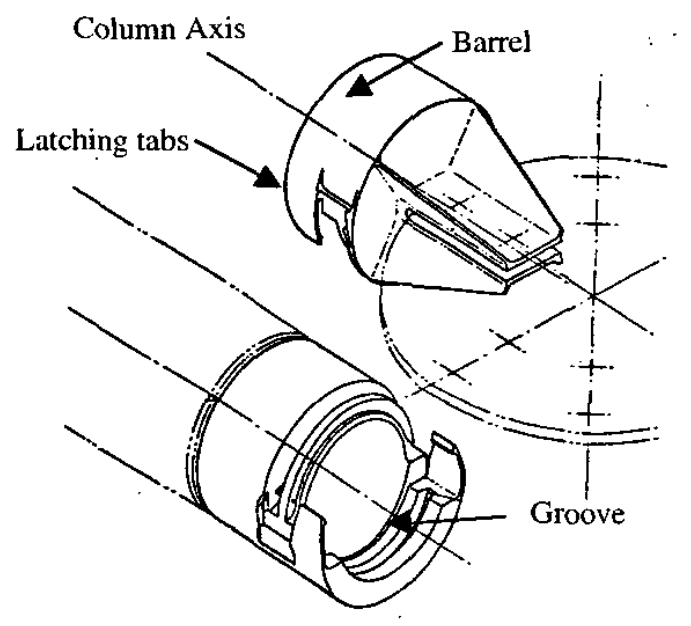

a - Snap-Joint

Figure 9 - Quick Attachment Joint Development 


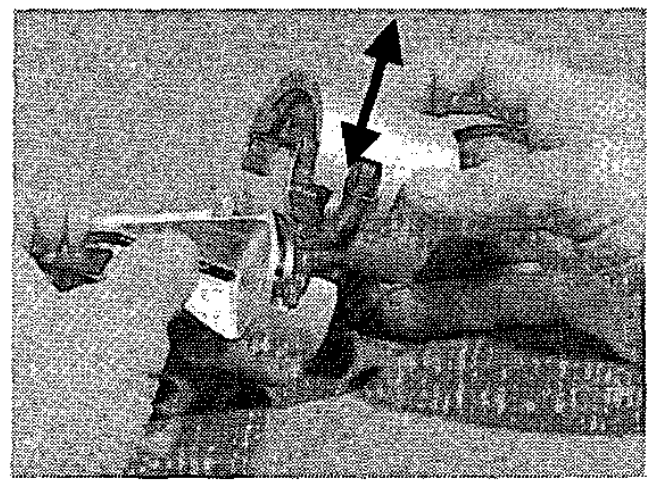

b - Operation of Quick-Attachment Latch Joint

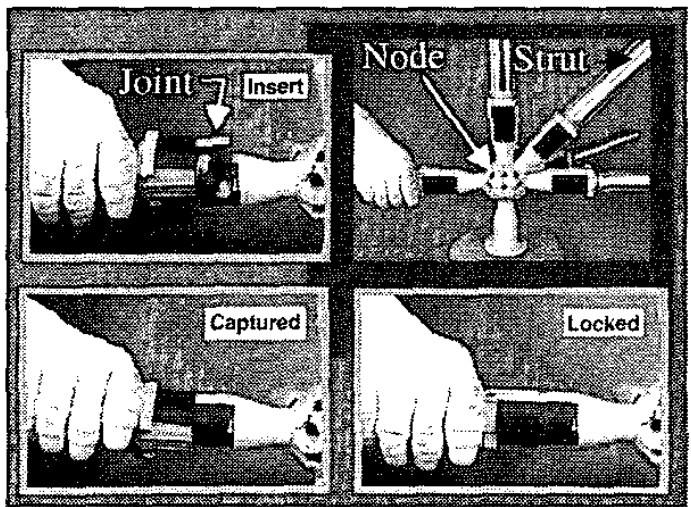

d - 5 Centimeter Quick-Attachment, Quick-Release Structural Joint

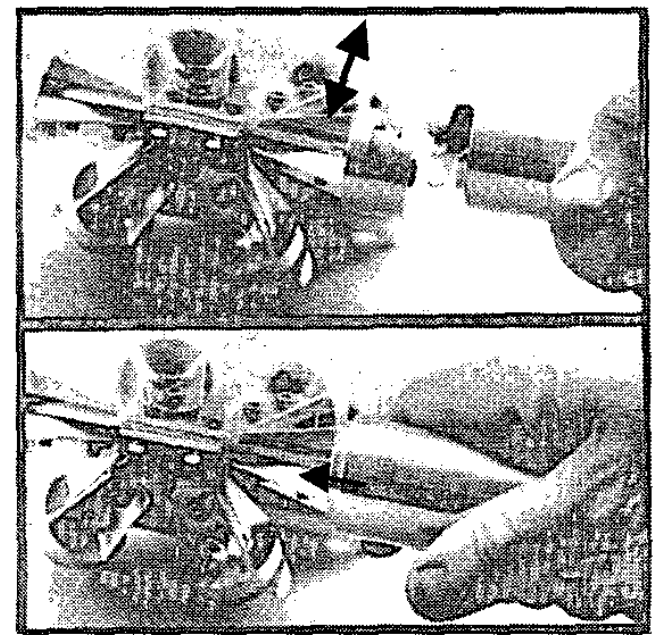

c - Quick-Attachment Sleeve Joint

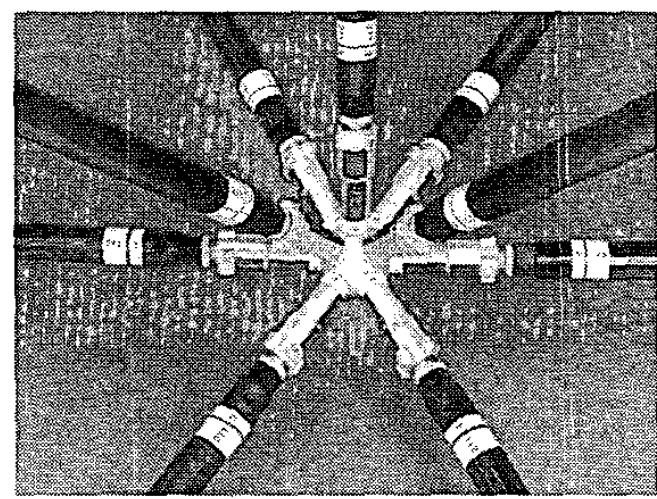

e - 2.54 Centimeter Quick-Attachment, Quick-Release Structural Joint

Figure 9 cont. - Quick Attachment Joint Development

\section{CONSTRUCTION STUDIES}

From the mid-1970's through the early 1990's LaRC conducted several construction studies of large space structures. Six of these studies evaluated near-full to fullscale space structure hardware and assembly techniques in $1 \mathrm{~g}$, simulated $0-\mathrm{g}$ (neutral buoyancy in water tanks), and the 0 -g space environment. The $1-\mathrm{g}$ tests were performed in a shirt-sleeve environment. The simulated $0-\mathrm{g}$ were performed in scuba gear and in pressurized EVA suits. The $0-g$ space environment tests were flight tests performed in space in pressurized EVA suits. The assembly rates determined by the $1-\mathrm{g}$ and simulated 0 -g tests were used to determine water drag effects and to calculate an in-space assembly rate. The assembly tests were performed by test engineers from LaRC and supporting personnel, including astronauts from Johnson Space Center (JSC) and test subjects from Marshall Space Flight Center (MSFC). The 1-g tests were performed at LaRC. The simulated 0 -g tests were conducted at the MSFC neutral buoyancy simulator. The following is a description of each of the programs. 


\section{Manual Assembly of a Tetrahedral Cell $[2,118,19]$}

Description-In the late 1970 's, the first of a series of studies was conducted by LaRC to determine the potential for EVA assembly of erectable structures by astronauts. The first study was a manual EVA assembly where the only astronaut aids were foot restraints (FR), handrails and a simulated Space Shuttle Remote Manipulator System (RMS). The purpose of the study was to assess astronaut EVA capabilities in the assembly of large erectable structures under simulated 0 -g conditions.

Seventeen assembly tests were conducted on a regular six-strut tetrahedral cell, the repeating "element" of a large space truss. The cell was assembled on a Shuttle cargo bay mockup under simulated 0-gravity as shown in figure 10. The cell was comprised of six pre-assembled composite, nestable columns (struts), $5.4 \mathrm{~m}$ long with a maximum diameter of $10 \mathrm{~cm}$. All the struts were the same length and interchangeable. The joints were the first joint design, the snap-joint, shown in figure $9 a$. In addition to building the truss structure, a simulated equipment module was installed at the cell apex to demonstrate instrumentation attachment.

The columns and joints were assembled by two test subjects. The test subjects wore pressurized space suits. Two modes of assembly were evaluated, manual assembly and manual assembly using the RMS as a footrestraint. For manual assembly the crew had to remove and translate the struts out of the cargo bay to their assembly locations. They also had to translate along the cargo bay and up the length of the struts. The assembly required a great deal of effort to maintain body position while connecting the structural components. A variation on this assembly test was performed using a foot-restraint on a pole as shown in figure10. This assembly provided some relief to the effort of the strut assembly by providing a footrestraint to react assembly maneuvers. The manual assembly with RMS support improved the assembly effort by providing a movable foot-restraint, reducing the effort and the assembly rate.

Results-The time to complete the assembly of the tetrahedral cell using manual assembly was 29 minutes (min) or 5 min/column. Using the simulated RMS, the assembly rate was reduced to $3 \mathrm{~min} /$ column.

\section{Lessons Learned}

1) Unrestrained EVA operations are feasible, though significantly difficult and fatiguing.

2) Foot restraints free the test subjects' hands and allow them to react their assembly task loads. Assembly aids are the greatest contributor to improving the assembly performance by the test subjects.

3) The operational activities of the test subjects are appreciably restricted by the pressurized space suits. Hand grasping and rotating hardware, such as screws, quickly cause fatigue.

4) The columns are easily manipulated and passed by the test subjects, but once the joints are assembled, verification of the joint connections is difficult.

5) Totally manual assembly quickly becomes impractical as the size of the structure increases.

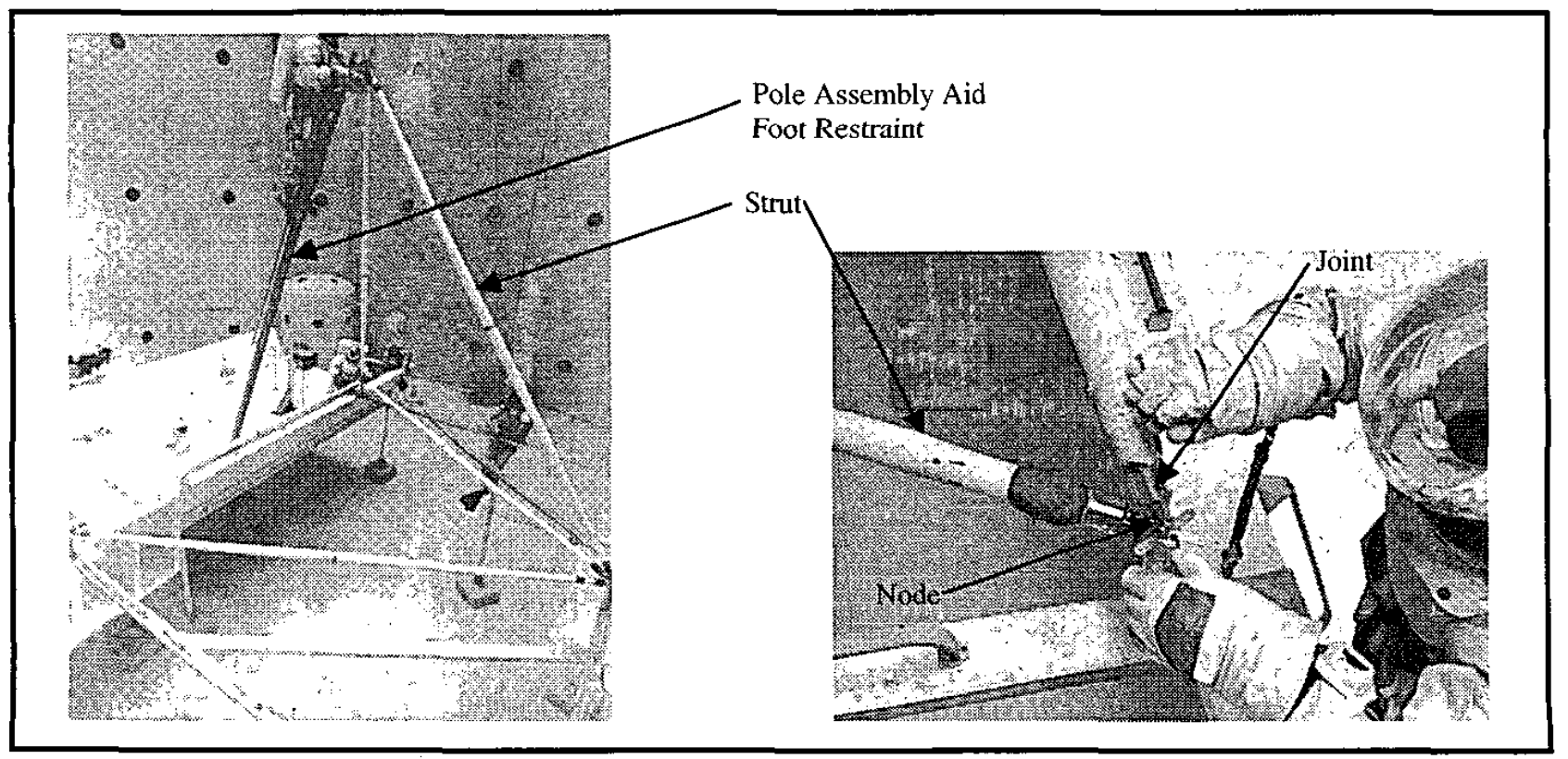

Figure 10 - Manual Assembly of a Tetrahedral Cell 


\section{Mobile Work Station Assembly of a Tetrahedral Truss}

\section{Beam $[13,18,19]$}

Description-The previous assembly test demonstrated that totally manual assembly quickly becomes impractical as the size of the structure increases. Therefore, the concept of a Mobile Work Station was developed to mechanically assist astronaut manual assembly of erectable space trusses, figure 11 . The next series of assembly tests, in 1980 , were conducted to evaluate the Mobile Work Station concept. The tests evaluated the assembly of a tetrahedral-truss beam by sets of two test subjects in a $1-\mathrm{g}$ shirt sleeve environment and in a simulated 0 -g environment, with and without pressurized (space) suits. The beam was assembled from 38 identical and interchangeable graphite-epoxy nestable-column struts (figures 7 and 8 ). The struts were $5.4 \mathrm{~m}$ in length with quick-attachment latch-joints (figure 9b). When assembled, the tetrahedral beam was approximately 16.5 $\mathrm{m}$ long and $4.5 \mathrm{~m}$ on each of the four sides of its diamond-shaped cross-section. The Mobile Work Station included movable platforms, controlled by a remote operator to transport workers and truss components. This relieved the workers of primary energy expending tasks. The test subjects remained attached to foot restraints on these platforms at all times during the assembly and were thus always in position to react assembly task loads. Assembly procedures were based on assembly line techniques where a few simple repetitive tasks, such as unstowing the struts and nodes and installing them on the assembly fixture, could be accomplished by hand. The truss was assembled one bay at a time on the assembly fixture. When one bay was completed, it was mechanically indexed along guide rails out of the work area. The next section was built behind it.
Results-The assembly of the full 38 element truss was demonstrated in $1 \mathrm{-g}$, in $0-\mathrm{g}$ scuba and in $0-\mathrm{g}$ pressure suited assembly. In $1 \mathrm{gg}$ the assembly rate was $24 \mathrm{~second} / \mathrm{strut}$ ( $\mathrm{sec} / \mathrm{strut}$ ). In simulated $0-\mathrm{g}$ in scuba gear the assembly rate was $39 \mathrm{sec} / \mathrm{strut}$. In simulated $0-\mathrm{g}$ in pressure suit the assembly rate was $53 \mathrm{sec} /$ strut. Taking into account the water drag during the simulated 0 -g assembly of truss, an average inspace assembly rate of approximately $38 \mathrm{sec} / \mathrm{strut}$ was calculated.

\section{Lessons Learned-}

1) The assembly line technique in combination with the Mobile Work Station fixture enables rapid assembly of the truss.

2) Movable work platforms that transport workers and the truss components eliminate primary energy-expending tasks that fatigue the workers. Stowage of the components near the crew provides for easy access and greatly facilitates assembly.

3) Quick-attachment joints eliminated the need for truss construction tools.

4) $5 \mathrm{~cm}$ diameter strut/joint end fittings approach the maximum size that can be easily handled with pressurized suit gloves.

5) The construction tasks should be simple and repetitive. The repetitive nature of the assembly tasks lend themselves to preprogramming or electronic sequencing of the platform positions, with the assembly workers controlling the rate of the assembly sequence.

6) The Mobile Work Station virtually eliminates the dependence of translational times on the size of the structure.

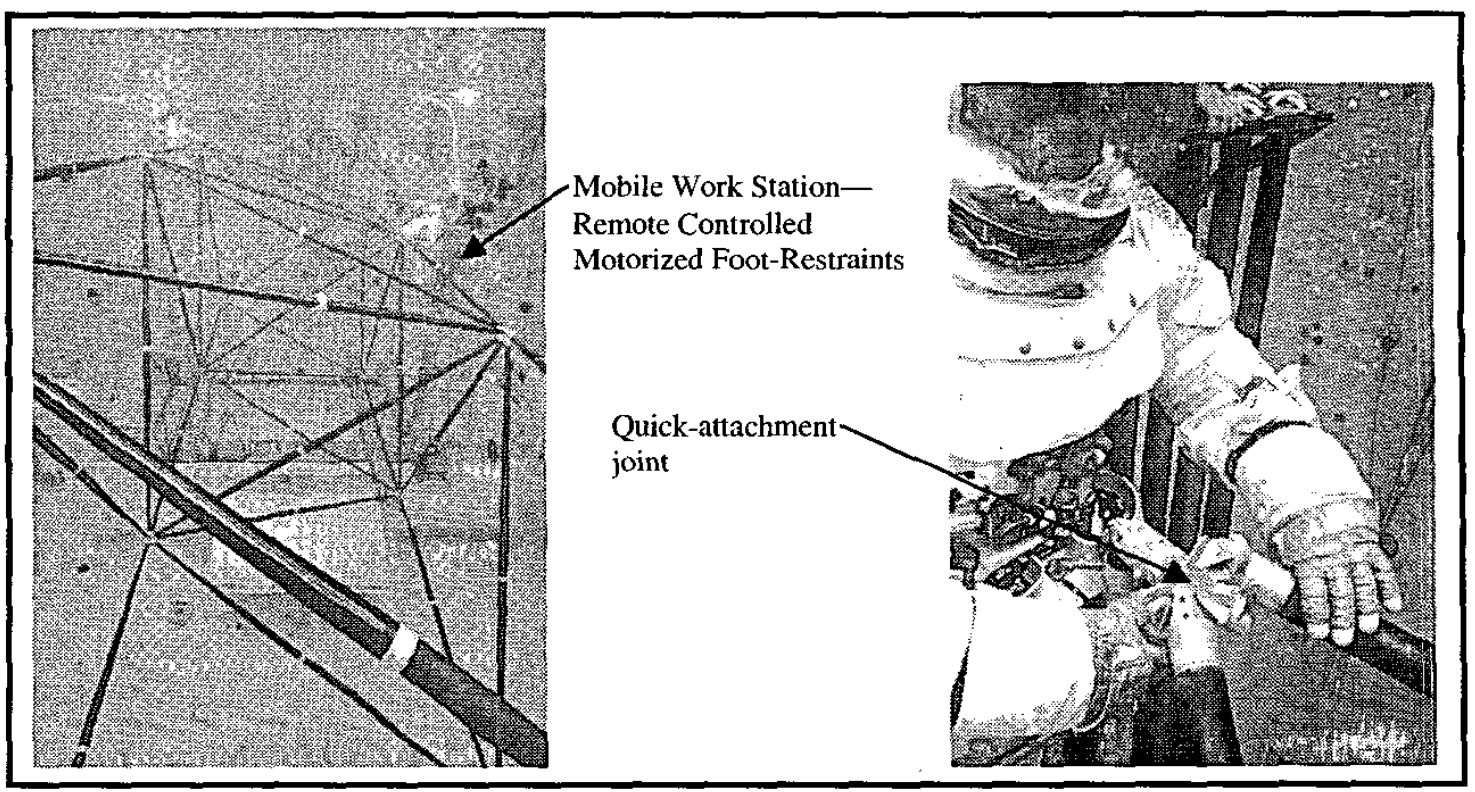

Figure 11 - Mobile Work Station Assembly of Tetrahedral Truss 
Swing-Am Beam Erector (SABER) truss beam assembly

$[14,18,19]$

Description-The next assembly concept study, conducted in 1984, was called the Swing-Arm Beam Erector (SABER). The SABER assembly concept evaluated the ability of a single EVA astronaut to assemble a truss structure. Like the Mobile Work Station, SABER eliminated astronaut manual translation by use of a motorized work platform with foot restraints. Tests were conducted in shirt sleeve l-g environment, and with and without pressure suits in a simulated $0-\mathrm{g}$ environment (neutral buoyancy). The tests involved the assembly of a tetrahedral truss-beam by a single test subject in simulated 0 -g as shown in figure 12. SABER uses a work platform to which a single astronaut is secured in foot restraints. The foot restraints were on-a telescoping swing-arm controlled by a remote operator. The work platform was moved to strategic work positions within a prescribed work envelope; thus, astronaut manual translation tasks were eliminated. A three-bay truss-beam was assembled from 30 aluminum struts $(1.6 \mathrm{~m}$ and $1.9 \mathrm{~m}$ in length, 2.5 $\mathrm{cm}$ in diameter) with quick-attachment sleeve-joints (figure $9 \mathrm{c}$ ) and 12 connecting nodes. Equal length struts were interchangeable. The struts and nodes were stowed within reach of the test subject on the swing-arm platform. The test subject assembled a bay of the structure on the assembly fixture. When one bay of the truss-beam was assembled, the bay was mechanically advanced one bay length along its axis to clear the work site for assembly of a succeeding bay. The assembled 3-bay truss was approximately $5.2 \mathrm{~m}$ long with an equilateral triangular cross section of side length $1.53 \mathrm{~m}$.

Results-The results showed that average on-orbit assembly rates of $29 \mathrm{sec} / \mathrm{strut}$ can be expected for struts of the size employed in these tests. The equivalent of an $26 \mathrm{~m}$ trussbeam ( 15 bays; 150 struts and 48 nodes) was assembled in 5 assemblies, during a 1 hour and 44 minute simulated $0-\mathrm{g}$ extravehicular activity period.

\section{Lessons Learned-}

1) Because of the repetitiveness of the steps, the test subject and console operator quickly learned the procedure during the first several tests. Little voice communication is needed for subsequent tests.

2) Like the Mobile Work Station, using the SABER motorized foot-restraint to transport the astronaut and the building material to the required work positions eliminates the primary source of astronaut fatigue in extravehicular activity (EVA); thus, astronaut productivity is greatly enhanced.

3) The $2.54 \mathrm{~cm}$ diameter struts/joints are easily handled by the pressure-suited subjects.

4) The handling of two different length struts during assembly is acceptable provided the struts are clearly marked.

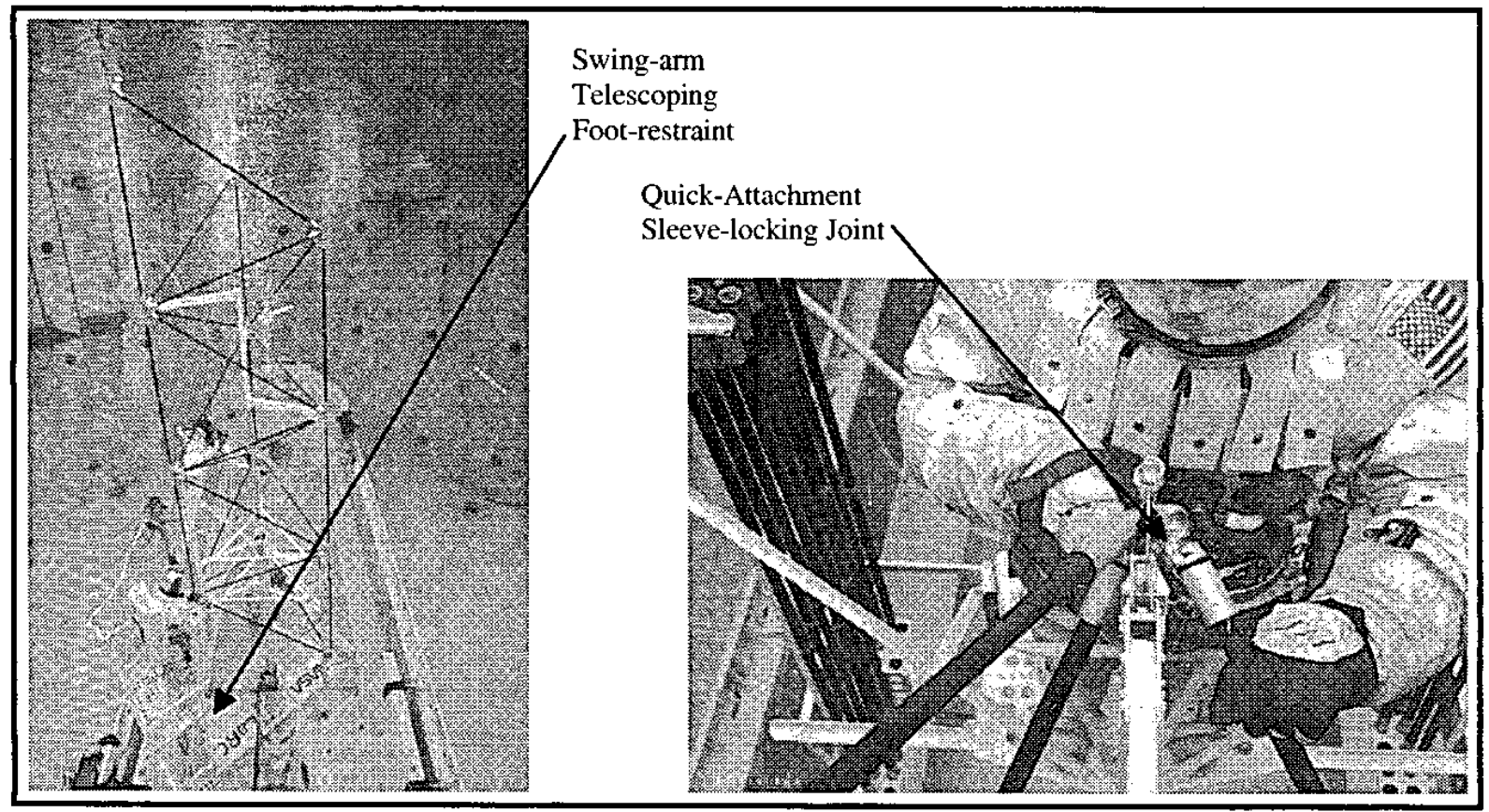

Figure 12 - SABER Assembly of Tetrahedral Truss Beam 
Assembly Concept for Construction of Erectable Space

Structure (ACCESS)[15, 18, 19]

Description-The ACCESS (Assembly Concept for Construction of Erectable Space Structure) experiment was launched on the Orbiter Atlantis on Nov. 26, 1985. ACCESS was designed to study manual assembly of a 13.7 meter long truss structure by two astronauts working in space suits in the Space Shuttle cargo bay.

The objectives of ACCESS were to: (1) evaluate an assembly line technique for effective use of astronauts as space construction workers, (2) provide on-orbit data for correlation of assembly rates and techniques developed in neutral buoyancy simulations, (3) gain on-orbit EVA construction experience, and (4) evaluate assermbly, handling, and maintenance of a large space structure in support of Space Station development. To meet these objectives ACCESS was divided into two parts, a baseline experiment and an expanded experiment.

The baseline experiment (figure 13a) involved an assembly line method of construction which enabled the astronauts to work at a fixed station. The struts and nodes were made readily accessible so that the astronauts were not required to leave the foot restraints during the assembly. The truss was assembled one bay at a time on the lower half of assembly fixture guide rails that were two bays long. The truss was composed of: (1) longerons (main vertical struts), (2) diagonals (bracing struts for the square bays of the truss), and (3) battens (horizontal struts that maintain the triangular cross section of the truss). The battens and longerons were all $1.4 \mathrm{~m}$ long, the diagonals were $1.9 \mathrm{~m}$ long, and all struts were $2.54 \mathrm{~cm}$ in diameter. Equal length struts were interchangeable. The joints were the quick-attachment sleeve-joints shown in figure $9 \mathrm{~d}$. To form the complete 10-bay truss, 93 struts were handled and interconnected at 33 nodes.

The expanded experiment used the Shuttle RMS and its Manipulator Foot Restraint (MFR) as a mobile work station to assist an astronaut in performing selected construction tasks. These tasks included: (1) assembly of the topmost bay, (2) installation of simulated electrical cable (figure 13c), (3) replacement of a strut and a node in an interior bay to simulate truss repair, and (4) detachment of the truss from the assembly fixture, manual manipulation of the truss, and reattachment to the assembly fixture.

Results-All basic EVA space construction tasks, both the baseline and the expanded experiments, were accomplished successfully in space. For the baseline assembly of the truss the simulated zero-g with pressure suit assembly rate was 14 $\mathrm{sec} / \mathrm{strut}$, with the full structure being assembled in $21.7 \mathrm{~min}$. The average assembly time for the $13.7 \mathrm{~m}$ truss in space was $16 \mathrm{sec} / \mathrm{strut}$, with the full structure being assembled in 25.5 min. The results demonstrated that erectable structure could be assembled effectively by astronauts in EVA. All four tasks in the expanded experiment were also completed successfully. While the RMS supported assembly of the top bay was accomplished, it was noted by the EVA astronaut that the desired assembly method was the baseline method using the fixed foot restraints. The repair demonstration showed the ability to remove a strut and then replace it without adversely affecting the truss structure. Cable attachment and the manual manipulation of the truss were also easily accomplished.

\section{Lessons Learned-}

1) In-space assembly is demonstrated.

2) Untethered operations handling 500 pieces is demonstrated without a mishap. The work level to handle the ACCESS size hardware in the space environment is reported to be essentially the same as experienced in the simulated space environment (neutral buoyancy).

3) Simulated 0 -g with pressure suit assembly times are shown to reliably estimate in-space assembly times for this class of structure.

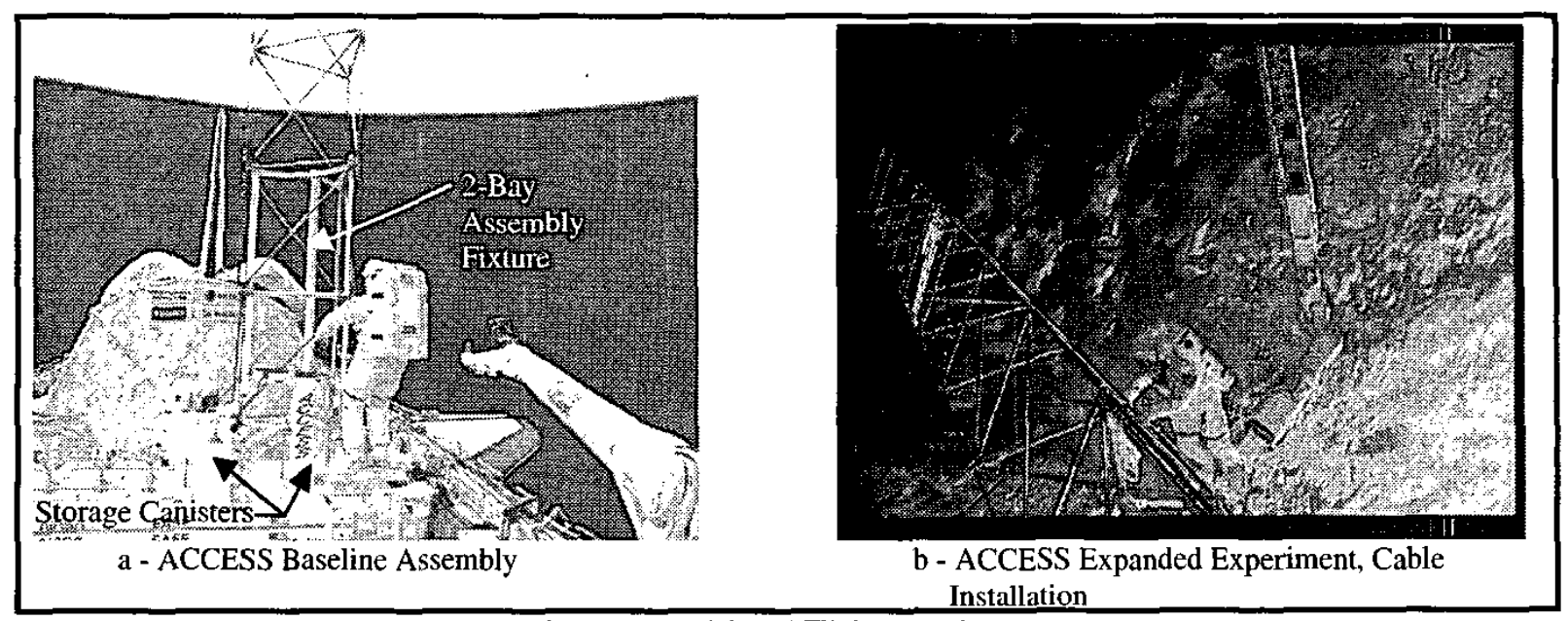

Figure 13 - ACCESS Flight Experiment 


\section{Mobile Transporter (MT) Assembly of Space Station}

Freedom (SSF) Truss $[16,18,19]$

Description-After the success of the ACCESS flight experiment and the results of a Space Station assembly concept study [20], a concept for the assembly of the base-lined SSF erectable keel was evaluated. The keel structure was an erectable truss beam 110 meter in length, with a $5 \mathrm{~m}$ square cross-section. A Mobile Transporter concept, based on the Mobile Work Station construction fixture, was proposed as an EVA assembly aid. The truss would be assembled out of the Space Shuttle cargo bay using the MT as a construction base, and two EVA astronauts would perform all construction tasks. To demonstrate this concept LaRC developed a l-g version of the Mobile Transporter and evaluated $1 \mathrm{-g}$ and simulated 0-g assembly of the truss structure in 1988 .

A three-bay orthogonal tetrahedral truss beam, consisting of 44 struts $5 \mathrm{~cm}$ in diameter and 16 nodes, was assembled repeatedly in neutral buoyancy by sets of two pressure-suited test subjects working from astronaut positioning devices (APDs) on the MT (figure 14). The orthogonal tetrahedral truss had cubic bays $4.6 \mathrm{~m}$ long. Two lengths of struts, $4.6 \mathrm{~m}$ and $6.5 \mathrm{~m}$ were used. The joints used were the quick-attachment, quick-release structural joints shown in figure 9d. A concept for integration of utility trays during truss assembly was also demonstrated in the assembly tests.

Three bays of truss were assembled at a time. Each bay was assembled in the Mobile Transporter work area. The test subjects were translated to various work sites at a nominal rate of $0.3 \mathrm{~m} / \mathrm{sec}$. After a bay was assembled it was indexed out of the work site and the next bay was built behind it. Additional bays were built as needed.
Two neutrally buoyed utility tray systems were provided, one for each side of the three-bay truss. The trays connected to the truss structure at corresponding truss node locations using the same quick-attachment joint. These tubular members had end fittings identical to the strut end fittings and were used to attach the trays to the truss nodes during assembly. This utility tray integration procedure minimizes EVA handling of the trays by using self-deploying, fan-folded stacks of trays. A total of forty-eight bays of truss ( 34 of which included integrated installation of utility trays) were assembled by a single pair of pressure-suited test subjects.

Results-The results of these tests indicate that by using an MT equipped with APDs, rapid EVA assembly of space station-size truss structure conld be performed. The average unit assembly time for a single pair of experienced test subjects was $28 \mathrm{sec} / \mathrm{strut}$. During the last few builds the average time for completion of one bay with integration of utility trays was nearly constant at approximately $6 \mathrm{~min} / \mathrm{bay}$. At this assembly rate, the entire SSF (1987 baseline) truss structure could be assembled on orbit in slightly less than 2 hours, not including payload attachments and subsystem integration.

\section{Lessons Learned-}

1) All the truss joint hardware is found to be EVA compatible.

2) The joint lock-up indicator is determined to be highly visible from long distances and easily interpreted by the test subjects and console operators.

3) Compatibility of the structural joints and the payload attachment joints (i.e., utility trays) made it easy to integrate the payload attachment into the assembly procedure with minimum impact on the assembly rate.

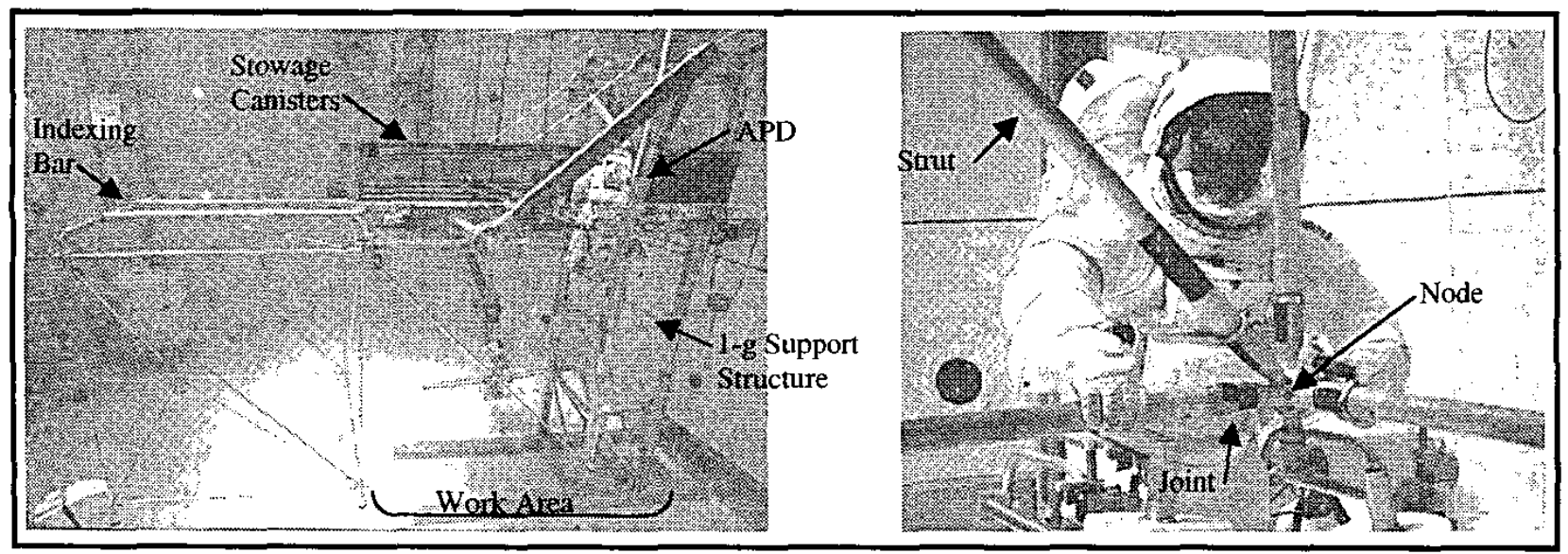

Figure 14 - Mobile Transporter Assembly of Space Station Freedom Truss 


\section{Precision Segmented Reflector (PSR) truss and panel}

assembly $[17,18,19]$

Description-During the mid-80's and early 90's, NASA studied several large reflector concepts under the Large Deployable Reflector (LDR) Program. The LDR program focused on the development of a $20 \mathrm{~m}$-diameter, far-infrared telescope and considered many system performance issues such as dynamics and control of the deployed system. In support of this program the next assembly study performed by LaRC (1992) evaluated EVA assembly and repair of large (i.e., greater than $10 \mathrm{~m}$ diameter) segmented reflectors, supported by a truss, for space-based optical or radio-frequency science instruments. The goal of the assembly study was to demonstrate the feasibility of having astronauts perform a complicated assembly in EVA. Specifically, the study was to identify the techniques, equipment, and procedures necessary to make EVA assembly and repair of precision reflectors efficient and reliable. The hardware utilized in the tests was developed specifically for application to precision reflectors [21]. The test article, a $14 \mathrm{~m}$ diameter, offset-focus reflector, included a near-flightquality, 315-member, doubly curved support truss and 7 mockup reflector panels. The seven reflector panels represented a portion of the 37 total panels needed to fully populate the reflector. In past studies, many of the struts and nodes were interchangeable. In this study, to achieve the surface accuracy of a near-flight structure with a parabolic curved surface, each of the 84 nodes and the 315 struts was unique. The struts were fabricated to individual precision lengths between $1.98 \mathrm{~m}$ and $2.15 \mathrm{~m}$. Well-planned procedures and clear part identification were required so the EVA assembly would be straightforward and an assembly line procedure could be used for construction. The joints used were the $2.54 \mathrm{~cm}$ quickattachment quick-release joints shown in figure 9f. Each mockup reflector panel was approximately $2.3 \mathrm{~m}$ from corner to corner and $5 \mathrm{~cm}$ thick. The gap between the edges of adjacent panels was approximately $0.3 \mathrm{~cm}$. The panels were designed to approximate the curvature of the reflector surface.

Two pressure-suited test subjects performed the assembly tests. The subjects were positioned in movable foot restraints that were controlled remotely by an operator. The assembly tasks were divided between the two crew. One of the crew built the reflector structure and the other unstowed and presented the structural components to the builder. Both of the crew participated in the attachment of the panels. The panels were dispensed from a canister attached to an RMS simulator and positioned and attached on the truss structure by the crew. The test article was built three times over the course of nine simulated EVA's (figure 15). Each simulated EVA was planned for approximately three hours. Procedures for the removal and replacement of a damaged panel were qualitatively evaluated during two of the tests.

Results-The full truss assembly and attachment of the seven panels was accomplished in 3 hours and 7 minutes. An assembly rate of $33 \mathrm{sec} / \mathrm{strut}$ for the simulated $0-\mathrm{g}$ EVA was calculated. This rate includes the translation and positioning of the crewman at the work sites. The panels were attached at an average assembly rate of 2 minutes and 3 seconds per panel. Data from the tests indicate that a flight version of the designed structure (including all 37 reflector panels and neglecting subsystem integration) could be assembled in less than 5 hours - less than the 6 hours normally permitted for a single EVA. Furthermore, procedures for the removal and replacement of a damaged reflector panel were evaluated. It was shown that EVA replacement of a damaged reflector of this type is feasible with the use of appropriate EVA crew aids.

\section{Lessons Learned-}

1) Idle time for the assembly crew is reduced when tasks are sequenced and/or divided equitably between the crew. In addition, sequencing the tasks so that they are executed in parallel minimizes idle time including the maneuvering of the RMS or other mechanical positioning devices.

2) Productivity is maximized with easy EVA procedures and appropriate mechanical aids.

3) Free floating tasks are considered only in cases where tasks are easily and quickly accomplished in that mode, such as the locking of the panels onto the structure.

4) The reflector-panel installation procedures are designed to minimize risk of panel damage by only allowing the assembly crew to handle the non-reflective side of the panels.

5) The hardware numbering scheme and labels are easily visible eliminating the need for verbal prompting of the assembly steps.

6) For a complex structure such as this reflector truss ( 84 unique nodes and 315 unique struts), the well-planned procedures and identification greatly enabled the assembly line procedure and assembly rate. 


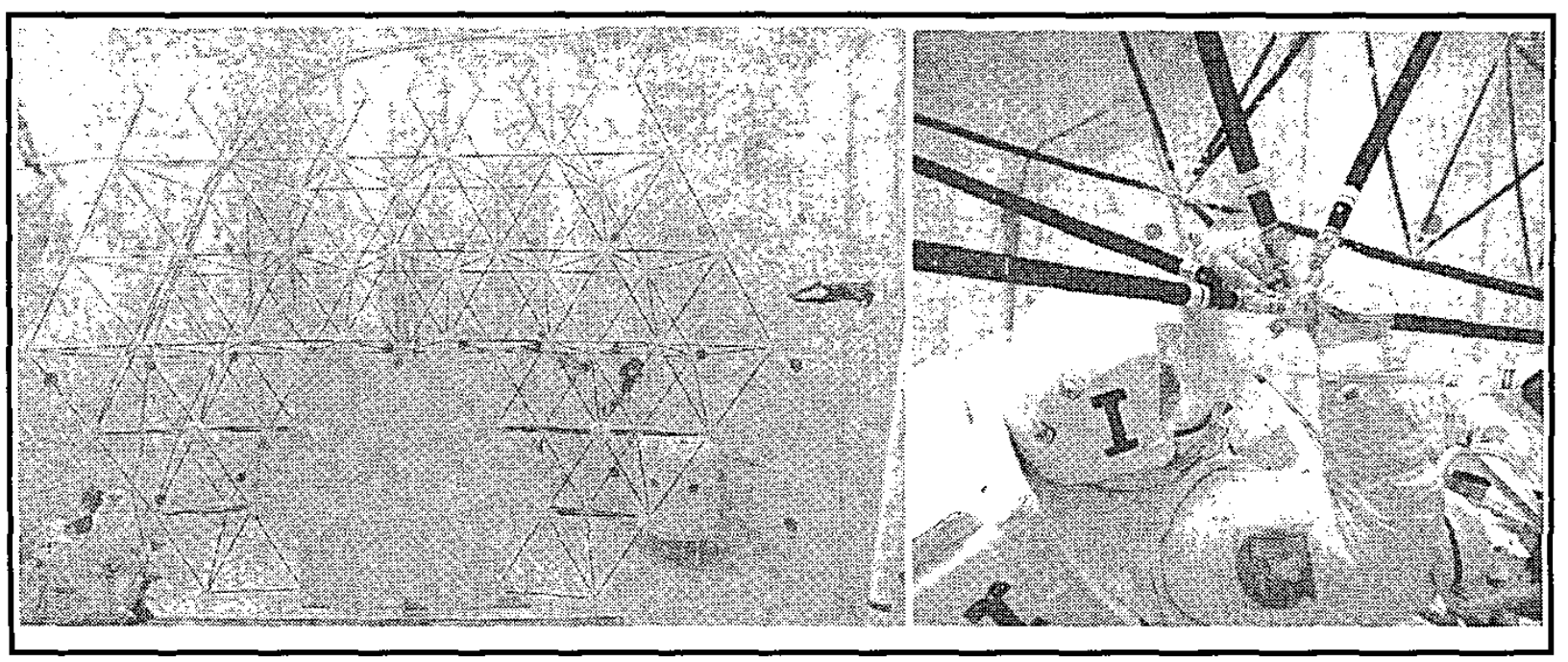

Figure 15 - Precision Segmented Reflector Assembly

\section{Summary of Construction Studies Results}

Table 1 contains a summary of the 6 assembly studies performed by NASA Langley Research Center. The table contains a description of the truss structure, the assembly aids, crew size, and assembly rates. Assembly rates are given for $\mathrm{I}-\mathrm{g}$, scuba $0-\mathrm{g}$, simulated space (neutral buoyancy) $0-\mathrm{g}$ and in-space $0-\mathrm{g}$. The $\mathrm{l}-\mathrm{g}$ and scuba $0-\mathrm{g}$ are compared with the simulated $0-\mathrm{g}$ rates to determine the effects of the space suit and water drag on the assembly rate. For SABER and ACCESS there is not an appreciable difference in the $1-\mathrm{g}$ and scuba $0-\mathrm{g}$ rates. This indicates there is no water drag effect on the smaller joint and strut size. SABER shows an increased rate for simulated $0-\mathrm{g}$ which can be attributed to the suit restrictions. ACCESS shows no change from scuba 0-g to simulated $0-\mathrm{g}$, possibly because the ACCESS subjects were using the newer Shuttle suits while the SABER subjects used the older Skylab-Apollo suits. The increase from simulated $0 \mathrm{~g}$ to space $0-\mathrm{g}$ rates for ACCESS are probably due to the newer, less functioned hardware used on orbit. For the larger structure assemblies, Mobile Work Station and Mobile Transporter, increases due to water drag and suit restrictions can be noted in the assembly rates. The calculated space 0 -g rates, except for PSR, are determined by removing the water drag rate effect from the total simulated 0 -g rate.

Also shown in the table, assembly rates are improved when motorized positioning aids are used. A comparison of in-space (demonstrated or calculated) assembly rates indicates that for all assembly tasks with assembly fixtures and foot restraints (motorized or stationary) there is little difference in the rates. Both two-man and oneman assemblies can be accomplished at reasonable assembly rates of approximately 40 seconds or less per strut. Most of the structural assemblies could be accomplished within the time frame of a typical EVA $(6$ hours).

The following is a summary of the lessons learned for structural assembly:

1) Unrestrained or "free floating" EVA operations are feasible though significantly difficult and fatiguing. EVA tasks are generally much easier to perform from foot restraints.

2) Manual assembly quickly became impractical as the size of the structure increased.

3) Pressure suits appreciably restricted the motions of the crew, requiring the need to minimize hand motions and translations to prevent fatigue.

4) Foot restraints free the test subjects' hands and allowed them to react their generated forces

5) The assembly line technique in combination with motorized foot restraints and fixtures enable rapid assembly of the truss.

6) Translation aids used to transport workers and the truss components eliminate primary energy-expending tasks that fatigued the workers and greatly contributed to improve the assembly rate.

7) Using a mechanized work station the assembly rate is independent of overall size of the structure to be built.

8) The construction tasks should be simple and repetitive. The repetitive nature of the assembly tasks lends itself to preprogramming or electronic sequencing of the platform positions, with the assembly crew controlling the rate of the assembly sequence.

9) The quick-attachment, quick release structural joint provids a predictable structural joint as well as an easily handled joint.

10) $5 \mathrm{~cm}$ diameter strut/joint end fittings approach the maximum size that can be easily handled with pressurized suit gloves. The $2.54 \mathrm{~cm}$ joint was very easily handled. 
11) A joint pattern that indicates the lock/unlock positions of the joint is highly visible and easy to interpret.

12) The handling of different length struts during assembly was acceptable provided the struts were clearly marked.

13) Compatibility of the structural joints and the payload attachment joints make it easier to integrate the payload attachment into the assembly procedure with minimum impact on the assembly rates.

14) The smaller hardware (i.e., SABER, ACCESS, and PSR) work effort is not significantly different between neutral buoyancy $0-\mathrm{g}$ simulation and onorbit 0 -g assembly, actual and calculated.
15) Stowing the assembly hardware near the work site and translating it with the crew so the hardware is always in easy access allows the crew to easily unstow and then position and assemble the hardware components.

16) Equally distributing tasks to eliminate crew idleness and moving crew and equipment simultaneous reduces dead time.

17) The ACCESS flight experiment provided evidence that neutral buoyancy simulation provides reliable predictions of actual on-orbit assembly rates.

18) With proper positioning devices, detailed labeling of hardware, and extensive pre-planning of the assembly sequence, even complex structures having many unique components are assembled in a predictable and reasonable time.

Table 1. Summary of Structural Assembly Tests

\begin{tabular}{|c|c|c|c|c|c|c|}
\hline & $\begin{array}{c}\text { EVA manual } \\
\text { assembly } \\
\text { (late 1970s) }\end{array}$ & $\begin{array}{l}\text { Mobile Work } \\
\text { Station } \\
(1978) \\
\end{array}$ & $\begin{array}{l}\text { SABER } \\
(1984) \\
\end{array}$ & $\begin{array}{c}\text { ACCESS } \\
(1985) \\
\end{array}$ & $\begin{array}{c}\text { Mobile } \\
\text { Transporter } \\
(1988) \\
\end{array}$ & $\begin{array}{l}\text { PSR } \\
(1992) \\
\end{array}$ \\
\hline Truss type & Tetrahedral cell & $\begin{array}{l}\text { Tetrahedral } \\
\text { truss beam }\end{array}$ & $\begin{array}{l}\text { Tetrahedral } \\
\text { truss beam }\end{array}$ & $\begin{array}{c}\text { Triangular truss } \\
\text { beam }\end{array}$ & $\begin{array}{l}\text { Orthogonal } \\
\text { (cubic) truss } \\
\text { beam }\end{array}$ & $\begin{array}{l}\text { Tetrahedral curved } \\
\text { platform }\end{array}$ \\
\hline $\begin{array}{l}\text { Dimensions of } \\
\text { truss }\end{array}$ & \begin{tabular}{|c|} 
Equilateral \\
triangular base \\
with $5.4 \mathrm{~m}$ sides \\
$\mathrm{x} 4.67 \mathrm{~m}$ tall \\
\end{tabular} & $\begin{array}{c}16.5 \mathrm{~m} \times 4.5 \mathrm{~m} \\
\times 4.5 \mathrm{~m}\end{array}$ & \begin{tabular}{|c|}
$5.24 \mathrm{~m} \mathrm{x}$ \\
equilateral \\
triangle $\mathrm{c} / \mathrm{s}^{*}$ \\
$1.5 \mathrm{~m}$ on a side
\end{tabular} & $\begin{array}{c}13.7 \mathrm{~m} \mathrm{x} \\
\text { equilateral } \\
\text { triangle } \mathrm{c} / \mathrm{s} \\
1.4 \mathrm{~m} \text { on a side }\end{array}$ & $\begin{array}{c}13.7 \mathrm{~m} \times 4.57 \mathrm{~m} \\
\times 4.57 \mathrm{~m}\end{array}$ & $\begin{array}{l}14 \mathrm{~m} \text { diameter } \\
\sim 3 \text { m deep }\end{array}$ \\
\hline $\begin{array}{l}\text { Number of } \\
\text { struts }\end{array}$ & 6 & 38 & 30 & 93 & 41 & 315 \\
\hline Length of struts & $5.4 \mathrm{~m}$ & $5.4 \mathrm{~m}$ & $\begin{array}{c}1.62 \mathrm{~m} \text { and } 1.9 \\
\mathrm{~m}\end{array}$ & $1.4 \mathrm{~m}$ and $1.9 \mathrm{~m}$ & $\begin{array}{c}4.57 \mathrm{~m} \text { and } 6.46 \\
\mathrm{~m}\end{array}$ & $\begin{array}{c}\text { Variable lengths } \\
\text { between } 1.98 \text { and } \\
2.15 \mathrm{~m}\end{array}$ \\
\hline \multirow{2}{*}{$\begin{array}{l}\text { Number of } \\
\text { nodes }\end{array}$} & \multirow[t]{2}{*}{4} & \multirow[t]{2}{*}{14} & \multirow[t]{2}{*}{12} & \multirow[t]{2}{*}{33} & \multirow[t]{2}{*}{16} & 84 nodes \\
\hline & & & & & & 7 panels \\
\hline Joint type & snap joint & $\begin{array}{l}\text { quick attach } \\
\text { latch joint }\end{array}$ & $\begin{array}{l}\text { quick attach } \\
\text { sleeve joint }\end{array}$ & $\begin{array}{l}\text { quick attach } \\
\text { sleeve joint }\end{array}$ & $\begin{array}{l}\text { quick attach } \\
\text { quick release } \\
\text { joint }\end{array}$ & $\begin{array}{c}\text { quick attach } \\
\text { quick release joint }\end{array}$ \\
\hline Joint size & $\sim 5 \mathrm{~cm}$ & $\sim 5 \mathrm{~cm}$ & $2.54 \mathrm{~cm}$ & $2.54 \mathrm{~cm}$ & $5 \mathrm{~cm}$ & $2.54 \mathrm{~cm}$ \\
\hline $\begin{array}{l}\text { Crew size } \\
\text { EVA - } \\
\text { Controllers - }\end{array}$ & $\begin{array}{l}2 \\
0 \\
\end{array}$ & $\begin{array}{l}2 \\
1 \\
\end{array}$ & $\begin{array}{l}1 \\
1 \\
\end{array}$ & $\begin{array}{l}2 \\
0\end{array}$ & $\begin{array}{l}2 \\
2 \\
\end{array}$ & $\begin{array}{l}2 \\
1 \\
\end{array}$ \\
\hline Assembly aids & $\begin{array}{l}\text { FR, RMS, } \\
\text { handrails }\end{array}$ & $\begin{array}{c}\text { Motorized } \\
\text { positioning aids }\end{array}$ & $\begin{array}{c}\text { Motorized } \\
\text { positioning aids }\end{array}$ & $\begin{array}{l}\text { FR and } \\
\text { assembly } \\
\text { fixtures }\end{array}$ & $\begin{array}{c}\text { Motorized } \\
\text { positioning aids }\end{array}$ & $\begin{array}{c}\text { Motorized } \\
\text { positioning aid }\end{array}$ \\
\hline 1 -g rate & $\mathrm{NA}$ & $24 \mathrm{sec} / \mathrm{strut}$ & $18 \mathrm{sec} / \mathrm{strut}$ & NA & $20 \mathrm{sec} / \mathrm{strut}$ & NA \\
\hline Scuba 0-g rate & $\mathrm{NA}$ & $39 \mathrm{sec} / \mathrm{strut}$ & $18 \mathrm{sec} / \mathrm{strut}$ & $14 \mathrm{sec} / \mathrm{strut}$ & $23 \mathrm{sec} / \mathrm{strut}$ & $\mathrm{NA}$ \\
\hline $\begin{array}{l}\text { Simulated space } \\
0 \text {-g } \\
\text { (Neutral } \\
\text { Buoyancy) }\end{array}$ & $\begin{array}{c}5 \mathrm{~min} / \mathrm{strut} \\
\text { (manual) } \\
3 \mathrm{~min} / \mathrm{strut} \\
\text { (RMS assist) }\end{array}$ & $53 \mathrm{sec} / \mathrm{strut}$ & $29 \mathrm{sec} . / \mathrm{strut}$ & $14 \mathrm{sec} / \mathrm{strut}$ & $28 \mathrm{sec} / \mathrm{strut}$ & $\begin{array}{c}33 \mathrm{sec} / \mathrm{strut} \\
2 \mathrm{~min} 3 \mathrm{sec} / \text { panel }\end{array}$ \\
\hline Space 0-g & NA & $\begin{array}{l}\text { Calculated at } \\
38 \mathrm{sec} / \mathrm{strut}\end{array}$ & $\begin{array}{c}\text { Calculated at } 29 \\
\text { sec./strut }\end{array}$ & $\begin{array}{l}\text { Actual at } \\
17 \mathrm{sec} / \mathrm{strut}\end{array}$ & $\begin{array}{c}\text { Calculated at } 25 \\
\text { sec/strut }\end{array}$ & $\begin{array}{c}\text { Calculated at } \\
33 \mathrm{sec} . / \mathrm{strut} \\
2 \mathrm{~min} 3 \mathrm{sec} / \text { panel }\end{array}$ \\
\hline
\end{tabular}

$* \mathrm{c} / \mathrm{s}=$ cross-section 


\section{FUTURE APPLICATIONS}

The large space structure assembly studies conducted by NASA LaRC identified efficient ways of constructing large space structures using EVA astronauts and erectable truss structures. Structural hardware, struts and joints, was developed to expedite the assembly process. Motorized positioning aids and assembly line procedures were also developed to reduce the work load of the EVA astronauts and increase their construction productivity. These assembly methods were successfully demonstrated in simulated $0-\mathrm{g}$ and in space flight.

The next logical step was to apply the techniques and lessons learned to missions requiring large space structures. During the 1980s and 1990s many large structures were being proposed for exploration. Some of these future concepts included construction facilities and space cranes. These concepts were proposed because it was recognized that an in-space infrastructure would be needed to build some of the large mission vehicles proposed in the early 1990's. LaRC applied its knowledge from the large space structures construction studies to studies that conceptualized the design and construction of these on-orbit facilities [22-24]. A construction facility is shown in figure 16 . The construction facility was envisioned as a large construction area built out of SSFtype truss structure. A space crane concept would be part of the facility. The space crane was conceived as a positioning and assembly device that would support the assembly of the large space structures. Both the construction facility and the space crane would be built by EVA astronauts using erectable truss hardware. In the 1990 's a concept and design for the structure of the space crane was developed by LaRC and is shown in figure 17. If large structures are to be built, then construction facilities such as those referenced should be re-evaluated.

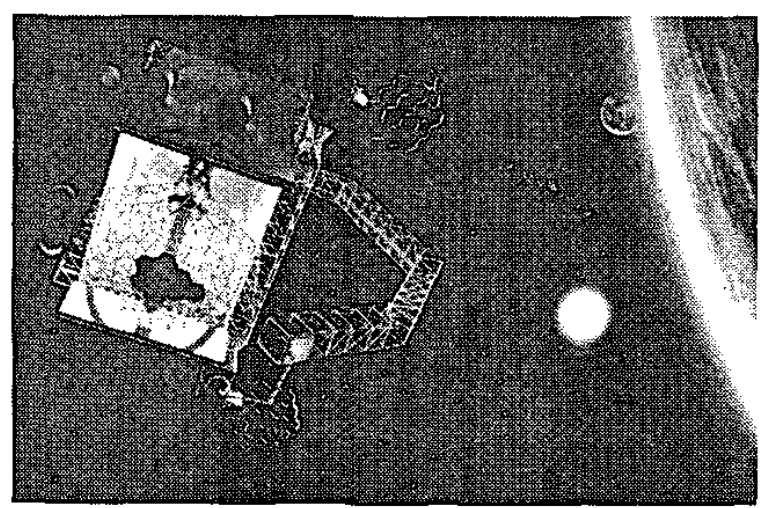

Figure 17 - Concept of Space Construction Facility Demonstration

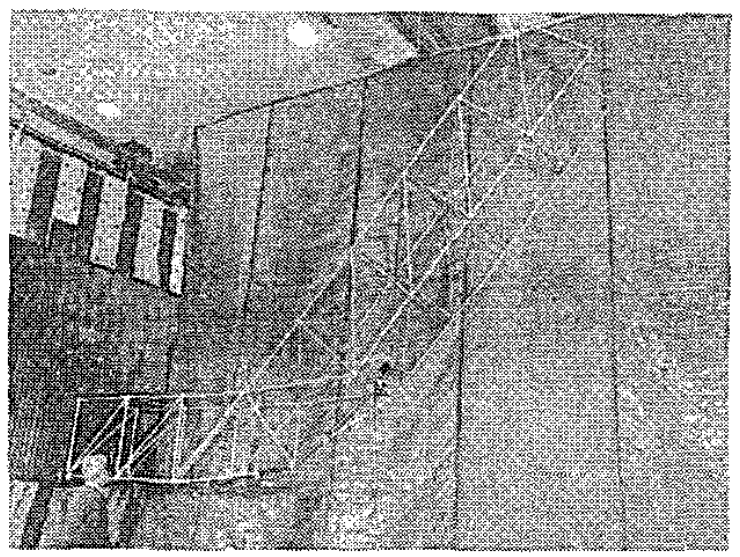

Figure 17 - LaRC Space Crane Structure

Future NASA missions may include 10 meter and greater diameter telescopes, 10 meter or greater diameter aeroshells for human exploration, and Solar Electric Propulsion vehicles with $100 \mathrm{~m}$ wing spans. The need for construction of these large structures is currently under investigation. One recent publication, reference 8 , addresses the construction of $25 \mathrm{~m}$ telescope structures using erectable structures. An analysis presented in the reference indicates that it is impractical to mechanically deploy a $25 \mathrm{~m}$ telescope mirror based on packaging, and that an erectable mirror is more efficient. The paper also explains that on-orbit assembly of the $25 \mathrm{~m}$ telescope mirror structure is within the capability of EVA or robotic assembly. The LaRC PSR assembly study is used as an example of how a $25 \mathrm{~m}$ structure could be built.

However there are limitations to EVA construction of erectable structures. As space structures become very large in size with thousands of parts and assembly steps human EVA construction becomes impractical [8]. At this point, robotic assembly of erectable structures should be considered. Currently the exact number of parts, assembly steps, and size of the structure versus cost and technology readiness levels of construction methods needed to determine when to use EVA and when to use robotics has not been assessed. Technology readiness levels for robotic assembly are still low but steps have been taken to address this option.

Langley developed a test program to assembly erectable structures using robotics. A description of this test program and results can be found in references 25 and 26. In the tests a truss support structure with flat reflector panels was assembled by automated robotics demonstrating the feasibility of robotic construction. A photo of the assembly is shown in figure 18 . 


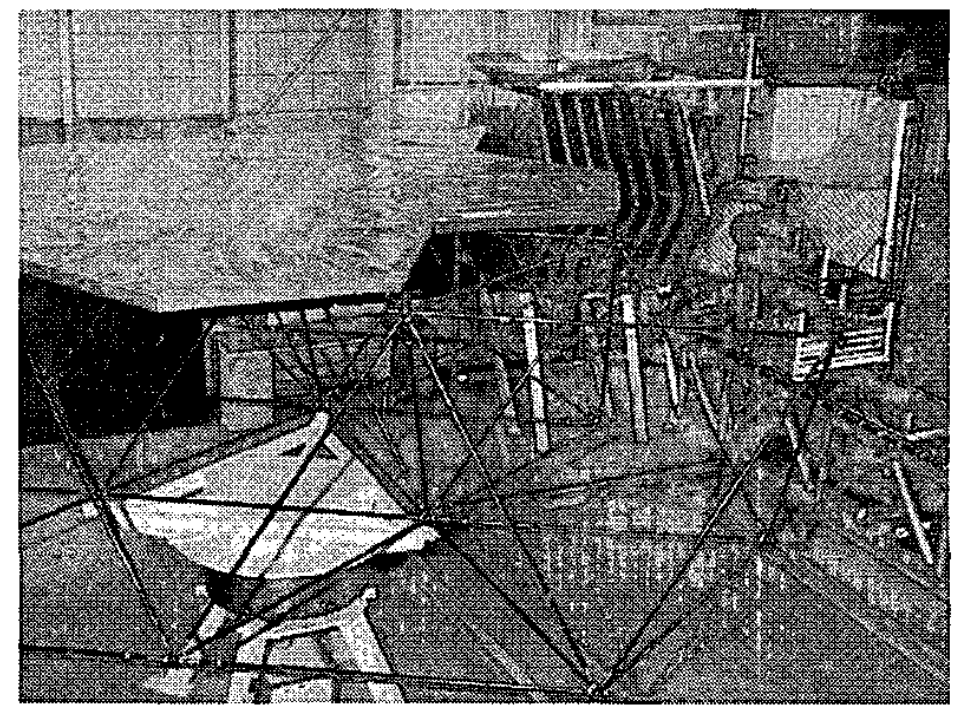

Figure 18 - Automated Robotic Assembly of Erectable Structure

Many of the lessons learned from the LaRC construction studies can be used to develop erectable assembly aids and procedures. An early study discussed in reference 23 looks at deployable assembly versus erectable assembly for the early space station concept. This study indicates trade spaces for consideration to determine which method to use. These trade spaces include growth of the facility, ability to accommodate a variety of payloads, integration of payloads and systems, EVA requirements, number of launches, cost, and truss structural performance. These trade spaces and others still provide valuable considerations for application to today's missions. Another study [27] discusses an analysis approach to determine the best construction methods to use based on a set of criteria. Figure 19 briefly outlines the steps to consider for assembly options. First, the mission objectives must be understood. Then the mission and spacecraft requirements, including spacecraft and structure design that will fulfill the mission requirements are developed. Next, without compromising the mission requirements, the different options for construction are examined. The different construction methods to be evaluated are deployable assembly, EVA erectable assembly, and robotic erectable assembly. Each of these methods has a variety of construction approaches. Deployables include mechanical and inflatable deployment. EVA erectables include motorized foot restraints. Robotic erectables include total automation and tele-robotics. After each construction approach is

evaluated, the feasibility of an integrated approach can be considered using the best options of each method.

The ISS is a current example of attempting to incorporate different assembly methods to construct a spacecraft system. ISS has erectable and deployable structures where large sections of pre-assembled structure are connected through tele-robotics (Shuttle RMS) and EVA connections of components and the solar arrays are deployable structures.

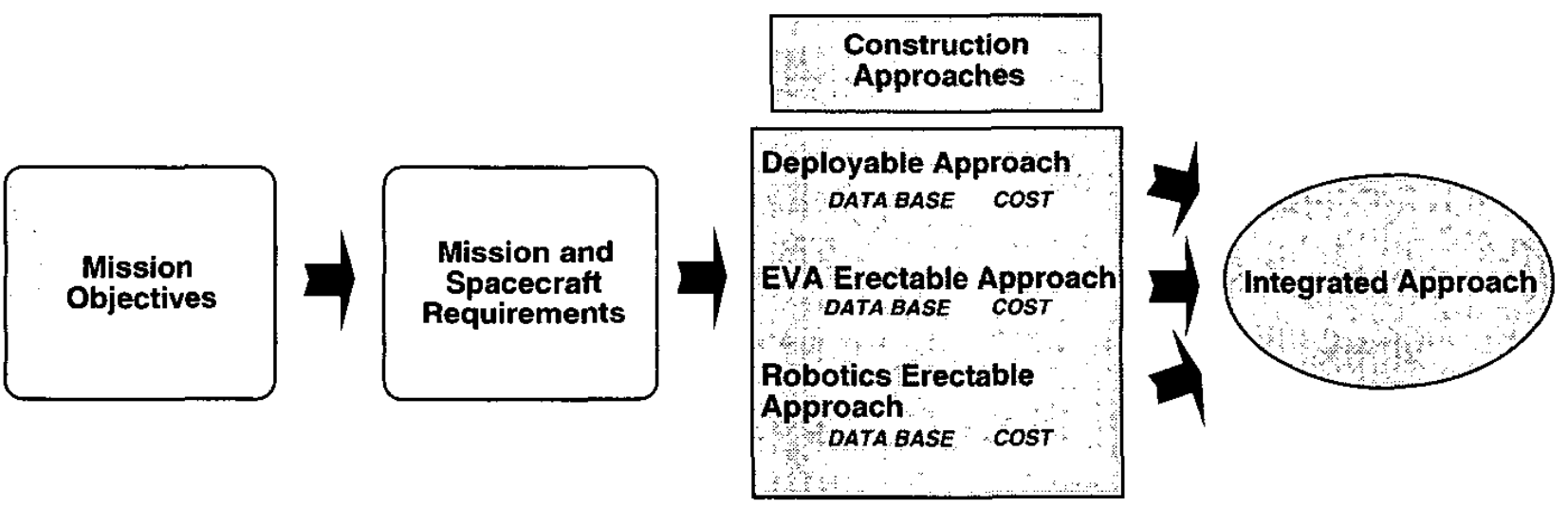

Figure 19 - Assembly Decision Process 


\section{CONCLUDING REMARKS}

An overview of the LaRC studies of the construction of erectable large space structures by astronauts has been presented, including a data base of assembly rates, lessons learned and a discussion of potential applications of the construction method.

The studies evaluated near-full to full-scale space structure hardware and assembly techniques in 1-g, simulated $0-\mathrm{g}$, and the space environment. Simulated $0-\mathrm{g}$ (neutral buoyancy) was determined to be a good simulation for space assembly. A comparison of in-space assembly rates indicated little difference in the rates between all studies using assembly fixtures and foot restraints (motorized or stationary). Both two-man and one-man assembly studies were accomplished at rates of approximately 40 seconds or less per strut.

Lessons learned from the EVA assembly studies demonstrate that using foot restraints instead of freefloating frees the EVA crew's hands to work. Mechanized translation aids allow the crew to be translated about the work site, access the hardware and reduce fatigue. Assembly line procedures with simple tasks enable a rapid assembly of the structure. An assembly joint developed to provide easy one-hand operations for EVA astronauts with a quick-attachment quick-release sidelatching operation also enables the assembly process as well as exhibits a linearly predictable structural performance.

Additional studies have shown the erectable construction method can be applied to large space structures for construction facilities and large aperature telescopes. Launch volume packaging, reliability, cost, structural performance, growth and maintenance, integration of payloads and systems, EVA requirements, and number of launches are examples of trade spaces that should be examined when selecting the construction method. Using an integrated approach of human and robotic erectable and deployable construction methods, cost and risk issues can be mitigated to achieve mass, size and versatility of the spacecraft structure. For any future large space structure, the assessment of the different construction methods and the use of an approach like the one described in reference 27 , can indicate the best construction method to use.

Though deployable structures have more in-space history, at this time deployable structures cannot efficiently achieve very large platform structures with reliable performance. To reach the size of space structures envisioned for future NASA missions the erectable construction approach provides many advantages and EVA erectable construction has been proven feasible. To plan for these missions, limitations need to be studied, costs realistically looked at, and time frames for mission implementation versus technology state-of-the-art must be considered. In addition, realistic demonstrations are required.

\section{REFERENCES}

[1] The Space Science Enterprise Strategic Plan, NASA NP2000-08-258-HQ, November 2000.

[2] Bement, Lawrence J.; Bush, Harold G.; Heard, Walter L., Jr.; and Stokes, Jack W., Jr.: EVA Assembly of a Large Space Structure Element, NASA TP-1872, 1981.

[3] Mikulas, Martin M.; Thomson, Mark: Flight-Vehicle Materials, Structures and Dynamics Assessment and Future Directions, Vol. 1, New and Projected Aeronautical and Space Systems, Design Concepts and Loads, Chapter 3: State of the Art and Technology Needs for Large Space Structures, ASME, 1994.

[4] Bowden, Mary L.: Space Vehicle Mechanisms. Elements of Successful Design, Chapter 16: Deployment Devices, New York: John Wiley and Sons, Inc., 1998.

[5] Lake, Mark S; Warren, Peter A; Peterson, Lee D.: A Revolute Joint with Linear Load-Displacement Response for a Deployable LIDAR Telescope, presented at the 30th Aerospace Mechanisms Symposium, May 1996, Hampton, Virginia.

[6] Peterson, L. D.; Lake, M. S.; Bullock, S. J.; Hachkowski, M. R.; Hinkle, J. D.; Warren, P. A.: Micron Accurate Deployable Antenna and Sensor Technology for NewMillennium-Era Spacecraft, University of Colorado, $\mathrm{Cu}-$ CAS-96-2, Jan. 1996.

[7] Heard, Walter L., Jr.; Bush, Harold G.; Walz, Joseph E.; and Rehder, John J: "Structural Sizing Considerations for Large Space Platforms", Journal of Spacecraft and Rockets, Vol 18 No. 6, 556-564, Nov.-Dec. 1981.

[8] Lake, Mark S.: "Launching a $25 \mathrm{~m}$ Space Telescope. Are Astronauts a Key to the Next Technically Logical Step Beyond NGST?" 2001 IEEE Aerospace Conference Proceedings, March 10-17, 2001.

[9] Powell, Denis J.; Browning, Lee: "Automated Fabrication of Large Space Structures", Astronautics and Aeronautics, Vol. 16 No. 10, 24-29, Oct. 1978.

[10] Goodwin, Charles J.: "Space Platforms for Building Large Space Structures", Astronautics and Aeronautics, Vol. 16 No. 10, 44-47, Oct. 1978.

[11] Bush, Harold G.; and Heard, Waiter L. Jr.: General Description of Nestable Column Structural and Assembly Technology, NASA TM-83255, Dec. 1981.

[12] Bush, Harold G., and Mikulas, Martin M.: A Nestable Tapered Column Concept for Large Space Structures. NASA TMX-73927, July 1976.

[13] Heard, Walter L.; Jr., Bush, Harold G.; Wallsom, Richard E.; and Jensen, J. Kermit: A Mobile Work Station Concept for Mechanically Aided Astronaut Assembly of Large Space Trusses, NASA TP-2108, 1983.

[14] Watson, Judith J.; Heard, Walter L., Jr.; and Jensen, J. Kermit: Swing-Arm Beam Erector (SABER) Concept for Single Astronaut Assembly of Space Structure, NASA TP$2379,1985$.

[15] Heard, Walter L., Jr.; et al.: Results of the ACCESS Space Construction Shuttle Flight Experiment, presented at the 
AIAA Space Systems Technology Conference, June 9-12, 1986, San Diego, Ca.

[16] Heard, Walter L., Jr.; et al.: Tests of an Alternate Mobile Transporter and Extravehicular Activity Assembly Procedure for the Space Station Freedom Truss, NASA TP-3245, October 1992.

[17] Lake, Mark S.; et al:: Evaluation of Hardware and Procedures for Astronaut Assembly and Repair of Large Precision Reflectors, NASA TP-2000-210317, August 2000.

[18] Heard, Walter L., Jr.; Watson, Judith J.; Ross, Jerry L.; Spring, Sherwood C.; and Havens, Kathryn A.: EVA Space Construction: Experience and Fundamental Issues, presented at the AAS 34th Annual Meeting, Nov. 1987, Houston, Tx.

[19] Heard, Walter L., Jr.; Watson, Judith J.; Spring, Sherwood C.; and Ross, Jerry L.: Astronaut/EVA Construction of Space Station, presented at the AIAA SDM Issues of International Space Station Meeting, April 1988, Williamsburg, Va.

[20] Mikulas, Martin M.; et al.: Deployable/Erectable Trade Study for Space Station Truss Structures, NASA TM-87573, July 1985.

[21] Bush, H. G.; et al.: Design and Fabrication of an Erectable Truss for Precision Segmented Reflector Application, Journal of Spacecraft and Rockets, Vol. 28 No. 2, 251-257, March-April 1991.

[22] Mikulas, Martin M. Jr.; and Dorsey, John T.: An Integrated In-Space Construction Facility for the 21 st Century, NASA TM-101515, Nov. 1988.

[23] Mikulas, M. M., Jr.; Davis, R. C.; and Greene, W. H.: A Space Crane Concept: Preliminary Design and Static Analysis, NASA TM-101498, Nov. 1988.

[24] Dorsey, John T.; Sutter, Thomas R.; Wu, Chauncey: A Structurally Adaptive Space Crane Concept for Assembling Space Systems On Orbit, presented at the Third International Conference on Adaptive Structures, Nov. 1992, San Diego, Ca.

[25] Rhodes, Marvin D.; Will, Ralph W.; and Quach, Coung: Baseline Tests of an Autonomous Telerobotic System for Assembly of Space Truss Structures, NASA TP-3448, July 1994.

[26] Doggett, William R.: Past Experience in Supenised Robotic Assembly of Truss Structures for Space Systems and Future Research Plans, to be presented at the 2002 IEEE Aerospace Conference, March 916, 2002, Big Sky, Mt.

[27]Analysis of Large Space Structures Assembly, Man/Machine Assembly Analysis, NASA CR-3751, under NAS8-32989, 1983, 1983.

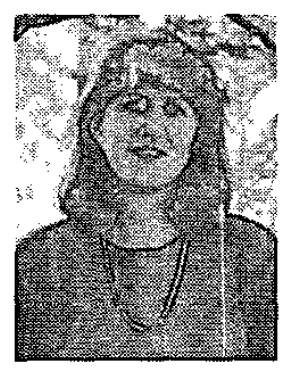

Ms. Watson is a research engineer in the Mechanics and Durability Branch $(M D B)$ at NASA Langley Research Center. She has a Bachelors of Science in Aerospace Engineering and a Master of Science in Engineering Mechanics. She has been emploved at NASA LaRC since 1977. Her primary field of research has been in conceptual design and testing of space structures. From 1983 through 1992, Ms Watson's research focused on the development and testing of large space structures for future applications, including assembly procedures and EVA techniques for astronauts. She has accumulated over 200 hours of scuba time and approximately 8 hours of EVA suit time during simulated $0-\mathrm{g}$ testing of assembly procedures for large space structures. She was the associate principal investigator for the ACCESS flight experiment on STS-61B in 1985. Currently Ms Watson is involved in two research programs; the investigation of the structural characterization of inflatable-rigidizable gossamer structures, and the integration of human and robotic procedures for in-space assembly operations.

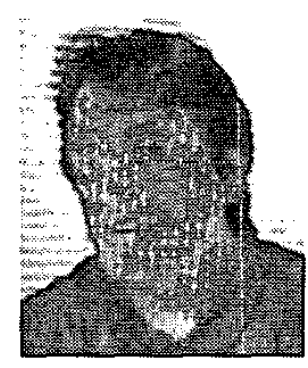

Mr. Collins is a structures research engineer at NASA Langley Research Center. He has a Bachelor's Degree in Physics and a Master of Science Degree in Mechanical and Aerospace Engineering. His primary areas of research have included the structural analysis and design of both aircraft and spacecraft structures. From 1987 through 1994 he was part a design and analysis team that developed structures for micron-precision segmented reflector applications. From 1994 through 1998, Mr. Collins served as lead engineer for the nonlinear analysis of composite fuselage concepts as part of NASA's High Speed Civil Transport Program. He also served on special assignment to the $X-33$ composite fuel tank failure investigation team. In addition, Mr. Collins has participated in numerous studies related to the design, packaging, and assembly of truss structures for in-space applications. He is currently involved with the analysis and test correlation of inflatable-rigidizable (gossamer-fype) structural columns, and is participating in studies aimed at the development of human/robotic concepts for in-space construction that are efficient in terms of both assembly and structural performance. 